\title{
Five new pseudocryptic land planarian species of Cratera (Platyhelminthes: Tricladida) unveiled through integrative taxonomy
}

\author{
Ana Paula Goulart Araujo ${ }^{1,2}$, Fernando Carbayo ${ }^{2,3}$, Marta Riutort ${ }^{4}$, Marta Álvarez-Presas ${ }^{\text {Corresp. } 4}$ \\ 1 Museu de Zoologia, Universidade de São Paulo, São Paulo, Brazil \\ 2 Laboratório de Ecologia e Evolução, Escola de Artes, Ciências e Humanidades, Universidade de São Paulo, São Paulo, Brazil \\ 3 Departamento de Zoologia, Instituto de Biociências, Universidade de São Paulo, São Paulo, Brazil \\ 4 Departament de Genètica, Microbiologia i Estadística, Facultat de Biologia and Institut de Recerca de la Biodiversitat (IRBio), Universitat de Barcelona, \\ Barcelona, Spain \\ Corresponding Author: Marta Álvarez-Presas \\ Email address: onaalvarez@ub.edu
}

Background. Cratera is a genus of land planarians endemic to the Brazilian Atlantic forest. The species of this genus are distinguished from each other by a series of external and internal characters, nonetheless they represent a challenging taxonomic issue due to the extreme alikeness of the species analysed in the present work. To resolve these difficulties, we have performed morphological analyses and used three nuclear markers (ribosomal 18S and 28S, Elongation Factor, a new anonymous marker named Tnuc813) and two mitochondrial fragments (Cytochrome oxidase I and a fragment encompassing NADH4 gene, trnF and the beginning of the Coxl gene) in an integrative taxonomic study.

Methods. To unveil cryptic species, we applied a molecular species delimitation approach based on molecular discovery methods, followed by a validation method. The putative species so delimited were then validated on the basis of diagnostic morphological features.

Results. We discovered and described four new species, namely Cratera assu, C. tui, C. boja, and C. imbiri. A fifth new species, $C$. paraitinga was not highly supported by molecular evidence, but was described because its morphological attributes are unique. Our study documents for the genus Cratera the presence of a number of highly similar species, a situation that is present also in other genera of land planarians. The high number of poorly differentiated and presumably recent speciation events might be explained by the recent geological history of the area. 
1 Five new pseudocryptic land planarian species of

2 Cratera (Platyhelminthes: Tricladida) unveiled through

3 integrative taxonomy

4

5

6 Ana Paula Goulart Araujo ${ }^{1,3}$, Fernando Carbayo ${ }^{2,3}$, Marta Riutort ${ }^{4}$, Marta Álvarez-Presas ${ }^{4}$

7

$8{ }^{1}$ Museu de Zoologia da Universidade de São Paulo, São Paulo, Brazil

9

${ }^{2}$ Departamento de Zoologia, Instituto de Biociências, Universidade de São Paulo, São Paulo, SP, Brazil

${ }^{3}$ Laboratório de Ecologia e Evolução, Escola de Artes, Ciências e Humanidades, Universidade de São Paulo, São Paulo, SP, Brazil

${ }^{4}$ Departament de Genètica, Microbiologia i Estadística, Facultat de Biologia and Institut de Recerca de la Biodiversitat (IRBio), Universitat de Barcelona, Barcelona, Catalonia, Spain

Corresponding Author:

Marta Álvarez-Presas ${ }^{4}$

Av. Diagonal 645, Barcelona, Catalonia, 08028, Spain

Email address: coseseries@gmail.com 


\section{Abstract}

30 Background. Cratera is a genus of land planarians endemic to the Brazilian Atlantic forest. The species of this genus are distinguished from each other by a series of external and internal characters, nonetheless they represent a challenging taxonomic issue due to the extreme

33

34 alikeness of the species analysed in the present work. To resolve these difficulties, we have performed morphological analyses and used three nuclear markers (ribosomal 18S and 28S, Elongation Factor, a new anonymous marker named Tnuc813) and two mitochondrial fragments (Cytochrome oxidase I and a fragment encompassing NADH4 gene, trnF and the beginning of the Cox1 gene) in an integrative taxonomic study.

Methods. To unveil cryptic species, we applied a molecular species delimitation approach based on molecular discovery methods, followed by a validation method. The putative species so delimited were then validated on the basis of diagnostic morphological features.

Results. We discovered and described four new species, namely Cratera assu, C. tui, C. boja, and $C$. imbiri. A fifth new species, $C$. paraitinga was not highly supported by molecular evidence, but was described because its morphological attributes are unique. Our study documents for the genus Cratera the presence of a number of highly similar species, a situation that is present also in other genera of land planarians. The high number of poorly differentiated and presumably recent speciation events might be explained by the recent geological history of the area.

\section{Introduction}

Land planarians (Platyhelminthes: Tricladida: Geoplanidae) are mostly soil inhabitants of forested areas. There are over 900 known species (Sluys, 2016), 332 of them belonging to Geoplaninae (http://planarias.each.usp.br; accessed in 18. March 2020), an exclusively Neotropical subfamily. Anatomy and histology of the copulatory apparatus are central for the identification and systematics of these organisms (e.g., E. M. Froehlich, 1955; Negrete \& Brusa, 2016). Nonetheless, when in several studies traditional, morphology-based taxonomic approaches were complemented with molecular methodologies, some nominal species were found to be polyphyletic (Sluys et al., 2016; Carbayo et al., 2018; Almeida, Marques \& Carbayo, 2019). Detailed reanalyses of the morphological evidence in those cases revealed that 
59

60

61

62

63

64

65

66

67

68

69

70

71

72

73

74

75

76

77

78

79

80

81

82

83

84

85

86

87

88

89

morphological variation assumed to represent within-species polymorphisms, actually signaled the existence of distinct species. From another perspective, such reinterpretation of intra-specific morphological variation revealed the presence of pseudocryptic species (see references above; Sáez \& Lozano, 2005).

The systematics of the Geoplaninae above the species level has benefited also from the molecular approach. Molecular phylogenetic analyses of this group revealed a number of polyphyletic genera. One of these genera, Geoplana Stimpson, 1857 subsequently being split into several genera (Carbayo et al., 2013). The genus Cratera Carbayo et al., 2013 emerged from Geoplana as a monophyletic group with 9 species to which were gradually added another 11 species with similar features (Carbayo \& Almeida, 2015; Negrete \& Brusa, 2016; Rossi et al., 2014, 2016; Rossi \& Leal-Zanchet, 2017; Lago-Barcia \& Carbayo, 2018; Boll et al., 2019). The most conspicuous diagnostic feature of Cratera is an ejaculatory duct with its distal section being widened (Marcus, 1951; Lago-Barcia \& Carbayo, 2018). However, this trait is not present in all members of the genus, probably as a result of secondary loss (Lago-Barcia \& Carbayo, 2018).

In the course of extensive land planarian samplings across the Atlantic forest we have found many individuals that can be attributed to the genus Cratera, most of them presenting very similar or even identical features in their external aspect or their internal anatomy. Given the presence of cryptic, or pseudocryptic species in other land planarian genera, we applied an integrative taxonomic analysis to unveil eventual cryptic species. We adopted the General Lineage Species Concept, which defines species as independently evolving metapopulation lineages (de Queiroz, 1998). In order to implement this concept, we used an integrative approach to species delimitations. First, we applied molecular species delimitation methods to delineate Primary Species Hypotheses (PSH) based on discovery methods, and thereafter used a validation method to formulate Secondary Species Hypotheses (SSH; Puillandre et al., 2012a). Hereafer, we tested whether the putative species exhibited morphological or anatomical features supporting their validity. In this manner, we unveiled four species for which molecular and morphological data agreed with each other. Molecular data of a putative fifth species did not fully support its distinctness, but morphological data did clearly pointed to its separate specific status and therefore we gave priority to the latter source of evidence.

\section{Materials \& Methods}




\section{Specimens sampling and morphological study}

Intensive samplings were performed in four protected forest areas in the States of Rio de Janeiro and São Paulo (Fig. 1). A number of people ranging between 5-8 performed each of two to 8-day field campaigns until reaching 200 hours sampling in each area (with the exception of Campos do Jordão, with 75 hours). Field experiments were approved by COTEC - Instituto Florestal do Estado de São Paulo (Proc. SMA 12.640/2011), Museu de Zoologia (EBBAut.020/2013) and Instituto Chico Mendes de Conservação da Biodiversidade (Proc. 32779-1; 11748-4). Animals were collected from the soil litter during the day and at night. The worms were photographed and, subsequently, killed in boiling water, after which a small tissue sample was taken and preserved in $100 \%$ ethanol for DNA extraction. Vouchers of frozen tissues are kept in FC's laboratory. The remaining part of the body was fixed in $10 \%$ formalin and, subsequently, transferred to $80 \%$ ethanol. Parts of the body were embedded in paraffin Histosec $\AA$, sectioned at intervals of 2-7 $\mu \mathrm{m}$, mounted on glass slides, and subsequently stained with Mallory method as modified by Cason (1950). Slides were examined with a compound microscope. Reconstruction drawings were done with a camera lucida attached to the microscope. Photomicrographs were taken with the help of a digital camera attached to the microscope. Enhancement of the contrast of the microphotographs and a whitish background of the photomicrographs were done with GIMP (GNU Image Manipulation Program 2.8.16; The GIMP team www.gimp.org, 1995-2016). Descriptions of the body color of live or preserved specimens follow the online RAL palette colors (C) RAL gemeinnützige GmbH, available at https://www.ral-farben.de/uebersicht-ral-classic-farben.html?\&L=1). Drawings and photomicrographs of sagittal and horizontal views are orientated with anterior extremity to the left. The width of the creeping sole was measured on transverse sections of the pre-pharyngeal region. Type material was deposited in the Museu de Zoologia da Universidade de São Paulo (MZUSP).

The electronic version of this article in Portable Document Format (PDF) will represent a published work according to the International Commission on Zoological Nomenclature (ICZN), and hence the new names contained in the electronic version are effectively published under that Code from the electronic edition alone. This published work and the nomenclatural acts it contains have been registered in ZooBank, the online registration system for the ICZN. The ZooBank LSIDs (Life Science Identifiers) can be resolved and the associated information viewed 
121 through any standard web browser by appending the LSID to the prefix http://zoobank.org/. The

122 LSID for this publication is: urn:lsid:zoobank.org:pub:F6B30CB7-6114-434F-9B2A-

123 A2F4CE625A20. The online version of this work is archived and available from the following

124 digital repositories: PeerJ, PubMed Central and CLOCKSS.

125

126 Molecular data acquisition

127 Extractions of genomic DNA were performed using the Wizard ${ }^{\circledR}$ Genomic DNA

128 Purification kit (Promega, Madison, WI, USA) following Álvarez-Presas et al. (2011). Two

129 mitochondrial and four nuclear markers were selected. The mitochondrial markers are a

130 cytochrome oxidase I gene fragment (hereafter referred to as COI), and a mitochondrial fragment

131 which includes the end of the nad4 gene, the entire sequence of trnF and the beginning of the

132 cox 1 gene. This latter marker, hereafter referred to as Nd4toCox 1 , is tested for the first time in

133 this work. The four nuclear genes correspond to the $18 \mathrm{~S}$ rDNA type II (18S), a fragment of the

134 28S rDNA (28S), a partial coding region of the elongation factor 1-alpha gene (hereafter referred

135 to as EF), and an anonymous nuclear marker (hereafter referred to as Tnuc813) developed from

136 NGS data (as detailed in Leria et al., 2020 and tested here for the first time. Primers used to

137 amplify and sequence the genes are mentioned in Table S1. For some individuals (indicated in

138 Table 1), it was not possible to obtain a long COI sequence ( $900 \mathrm{bp}$ ) of good quality (fragment

139 amplified by the BarS / COIR primers). To overcome this situation, a shorter fragment (COIF /

140 COIR primers), of $\sim 300 \mathrm{bp}$, was amplified. The polymerase chain reaction (PCR) amplification

$141(25 \mu \mathrm{L})$ was performed on a Techne ${ }^{\circledR}$ TC-5000TM (Bibby Scientific Ltd, Staffordshire, UK)

142 and on an Eppendorf Mastercycler® (Eppendorf, Hamburg, Germany) personal thermocyclers

143 using initial denaturation step of $5 \mathrm{~min}$ at $92-95^{\circ} \mathrm{C}$, followed by $30-35$ cycles of 30 - to $50-\mathrm{s}$

144 denaturation at $94-95{ }^{\circ} \mathrm{C}, 30$ - to $45-\mathrm{s}$ annealing at $44-54{ }^{\circ} \mathrm{C}$ and $50-\mathrm{s}-1-$ min extension at $72{ }^{\circ} \mathrm{C}$,

145 with a final extension step of $3-4 \mathrm{~min}$ at $72{ }^{\circ} \mathrm{C}$. The PCR results were verified using

146 electrophoresis of the amplification products on 1\% agarose gels stained with GelRed (Biotium,

147 Hayward, CA, USA), and visualized under UV transillumination. Amplification products were

148 purified with a vacuum manifold (Multiscreen ${ }^{\circledR} H T S$ Vacuum Manifold; Millipore Corporation,

149 Billerica, MA, USA). Purification products were sent to Macrogen (Amsterdam, Europe), where

150 both strands were sequenced by Sanger sequencing. Chromatograms were revised and contigs

PeerJ reviewing PDF | (2020:04:48478:1:1:NEW 8 Jul 2020) 
151 constructed in Geneious v 8.1.7. software (Biomatters; available from

152 http://www.geneious.com).

153 For all the coding genes (COI, Nd4toCox1, EF and Tnuc813), sequences were aligned

154 based on the amino acid sequences by using Clustal W (included in the BioEdit software 7.0.9.0

155 (Hall, 1999)). The genetic code 9 (Echinoderm and flatworms' mitochondrial) was used for 156 translating the mitochondrial genes. Ribosomal RNA gene sequences were aligned using the 157 online version of the software Mafft v7 (Katoh, Rozewicki \& Yamada, 2017) applying the G-

158 INS-i iterative refinement method. Misaligned or ambiguously aligned regions were removed 159 using Gblocks v0.91b program (Talavera \& Castresana, 2007), allowing 50 as a maximum 160 number of contiguous non-conserved positions and setting the minimum length of a block to 4 , 161 and allowing half gap positions allowed. Three different datasets were used for several analyses:

162 (1) COI dataset including COI sequences used for the ABGD and mPTP molecular species 163 delimitation approaches; (2) BPP datasets 18S, 28S, COI, Nd4toCox1, Tnuc813, and EF 164 independent alignments (completing some sequences with missing data (Ns); see Table 1) used 165 for the BPP molecular species delimitation analysis; and (3) concatenated dataset, including the 166 information of the six genes (18S, 28S, EF, Tnuc813, COI and Nd4toCox1), which was used to 167 infer a general phylogeny.

168 For the individual gene alignments, the DNA sequence evolution model that best fits the 169 data was estimated by using jModelTest v2.1.4 (Darriba et al., 2012), applying the Akaike 170 information criterion (AIC). For the concatenated dataset PartitionFinder2 version 2.1.1 (Lanfear 171 et al., 2017) was run on the CIPRES Science Gateway (Miller, Pfeiffer \& Schwartz, 2010) to 172 identify an appropriate partition scheme and their corresponding DNA evolutionary models. The 173 data were divided by gene, with unlinked branch lengths, the 'raxml' models for selection and the 174 AICc model selection criteria with the 'greedy' search algorithm. The phylogenetic trees for the 175 concatenated dataset were inferred using the Bayesian Inference (BI) method using MrBayes 176 software v3.2.6. (Ronquist et al., 2012) implemented in CIPRES and using BEAGLE (Ayres et 177 al., 2012), setting the evolutionary model and appropriate partitions according to the

178 PartitionFinder results with the unlinked parameters. Two runs of four chains were applied 179 producing 5 million generations and, for each of them, 5,000 trees were stored. It was checked 180 that the probability values (logarithm) of the cold chain reached the stationarity state and the 181 convergence of the two runs, verifying that the average standard deviation of the split 
182 frequencies was lower than 0.01. A default burn-in of $25 \%$ was used and a consensus tree was 183 obtained from the remaining trees. The maximum likelihood (ML) method was used to infer 184 phylogenies with the software IQtree v1.6.10 (Nguyen et al., 2015). The IQtree searches were 185 carried out using the default configuration in CIPRES, with a starting random tree (option - $t$ 186 RANDOM), and assessing branch support using 1000 ultrafast bootstrap approximation 187 replicates (Minh, Nguyen \& Von Haeseler, 2013). The best fit models for each partition were 188 selected by PartitionFinder and each partition was allowed to have its own set of branch lengths 189 (option -sp).

190

\section{Molecular species delimitation}

192

For the molecular species delimitation analyses, two discovery methods (ABGD and 193 mPTP) and one validation method (BPP) were applied. Using the COI dataset, the Automatic

194

195 196 197 198 199 200 201 202 203 204 205 206 207 208 209 210 Barcode Gap Discovery (ABGD) method (Puillandre et al., 2012b) was applied through the website http://wwwabi.snv.jussieu.fr/public/abgd/abgdweb.html. The default values of Pmin = 0.001 and $\operatorname{Pmax}=0.10$, steps $=10$ and number of intervals $=20$ were used, while also the relative gap width value $(\mathrm{X})=1.0$ and correcting the distance matrix under the K80 Kimura model with a MinSlope $=1.5$.

The multi-rate Poisson Tree Process (mPTP), which is another single locus analysis, was also used. This model incorporates different levels of intraspecific genetic diversity derived from differences in the evolutionary history or in the sampling of each species, accommodating different coalescence rates within the lineages (Kapli et al., 2017). mPTP analysis was performed in a ML tree reconstructed by IQtree in CIPRES with the COI dataset (Suppl Fig. 1). For this analysis the command line version of the mPTP $\mathrm{v}$ 0.2.4. software was used without considering the outgroup. Four independent runs of 5,000,000 Monte Carlo Markov chains (MCMC) were carried out, sampling every 10,000 generations. The use of these discovery methods leads to the Primary Species Hypothesis (PSH), used as starting point for the validation step.

For the validation step, a Bayesian multilocus method of delimiting species (Yang \& Rannala, 2010; Yang \& Rannala, 2014) implemented in the BPP v3.3 software (Yang, 2015) was applied. Different hypotheses of species delimitation and estimation of the posterior probability (PP) of each model were tested using reversible jump MCMC (rjMCMC). The previous species assignment resulting from the ABGD discovery analysis was used as a starting hypothesis for the 
213 BPP analysis, because it was the analysis that gave the largest number of PSHs. Some species 214 were excluded from this validation analysis because only one individual was available (Cratera 215 arucuia Lago-Barcia \& Carbayo, 2018 and Cratera picuia Lago-Barcia \& Carbayo, 2018) or 216 because it only had the COI gene sequenced (Cratera ochra Rossi et al., 2016). As these two 217 species were not the target species for our study, their removal from the analysis was not 218 relevant. A guide tree generated by 100 million generations (stored every 5000) in * BEAST2 219 v2.5.2 (Bouckaert et al., 2014) was built in CIPRES with the six single gene datasets (BPP 220 datasets), applying the evolutionary model for each gene resulting from the previous jmodeltest 221 analysis $(18 \mathrm{~S}=\mathrm{GTR}+\mathrm{I} ; 28 \mathrm{~S}=\mathrm{HKY}+\mathrm{I}+\mathrm{G} ; \mathrm{Cox} 1=\mathrm{GTR}+\mathrm{G} ; \mathrm{EF}=\mathrm{GTR}+\mathrm{I}+\mathrm{G} ; \mathrm{Nd} 4$ toCox $1=\mathrm{HKY}+\mathrm{I}+\mathrm{G}$ 222 and $\mathrm{Tnuc}=\mathrm{GTR}+\mathrm{I})$.

The molecular clock was set as log-normal-relaxed for all markers (unlinked) and the 224 speciation model to Birth and Death. In the BPP analysis, both the size of the ancestral

225 226 227 228 229 230 231 232 233 234 235 236 237 238 239 240 241 242 243 population (theta, $\theta$ ) and the time of origin for each species (tau, $\tau$ ) were parameterized with four different models (named M1-M4): M1 for large ancestral population size and deep divergence, G $(1,10)$ for $\theta$ and $\tau$; M2 for small ancestral population size and shallow divergence, $\mathrm{G}(2,1000)$ for $\theta$ and $\tau$; M3 for large ancestral population size and shallow divergence, $\mathrm{G}(110)$ for $\theta$ and $\mathrm{G}$ (2 1000) for $\tau$; and M4 for small ancestral population size and deep divergence, $G(2$ 1000) for $\theta$ and $\mathrm{G}(110)$ for $\tau$. The rjMCMC analysis was run under the algorithm 0 in 100,000 generations (with a sampling interval of 2) excluding $10 \%$ as burn-in. In order to test the robustness of the results, these executions were replicated using different starting seeds. These analyses were done without outgroup. Results of BPP lead to Secondary Species Hypotheses (SSH).

\author{
Abbreviations used in figures \\ (cg) cyanophil gland cells \\ (co) common glandular ovovitelline duct \\ (e) eye \\ (ed) dilated portion of ejaculatory duct \\ (ej) ejaculatory duct \\ (ep) esophagus \\ (fa) female atrium \\ (fc) female genital canal
}




$\begin{array}{ll}244 & \text { (fo) fold } \\ 245 & \text { (g) gonopore } \\ 246 & \text { (gl) glands } \\ 247 & \text { (i) intestine } \\ 248 & \text { (lc) longitudinal cutaneous muscle fibers } \\ 249 & \text { (m) muscle fiber } \\ 250 & \text { (ma) male genital atrium } \\ 251 & \text { (mc) common muscle coat } \\ 252 & \text { (mo) mouth } \\ 253 & \text { (o) ovary } \\ 254 & \text { (ov) ovovitelline duct } \\ 255 & \text { (ph) pharyngeal pouch } \\ 256 & \text { (pb) penis bulb } \\ 257 & \text { (pp) penis papilla } \\ 258 & \text { (px) pharynx } \\ 259 & \text { (sb) subintestinal transverse muscle fibers } \\ 260 & \text { (sd) sperm duct } \\ 261 & \text { (sg) shell glands } \\ 262 & \text { (sp) supraintestinal transverse muscle fibers } \\ 263 & \text { (t) testis } \\ 264 & \text { (vi) vitellaria } \\ 265 & \text { (vn) ventral nerve plate } \\ & \end{array}$

266

\section{Results}

268 Molecular datasets

269 The COI dataset consists of 40 sequences with a length of $822 \mathrm{bp}$, while the concatenated 270 dataset (28 Cratera sequences plus 3 outgroups from the genus Obama) has a length of $5671 \mathrm{bp}$. 271 The individual gene datasets for the *BEAST analysis are constituted by 26 sequences with a 272 length of 1349 bp (18S), 1544 bp (28S), 825 bp (COI), 612 bp (EF), 730 bp (Nd4toCox1) and 273611 bp (Tnuc813). 


\section{Phylogenetic analysis}

276

277

278

279

280

281

282

283

284

285

286

287

288

289

290

291

292

293

294

295

296

297

298

299

300

301

302

303

304

305

The partitions obtained with PartitionFinder and applied to the phylogenetic analysis of the concatenated dataset are Cox1_codon2, EF_codon2, 18S, Tnuc813-1_codon3, Tnuc8133_codon2, Tnuc813-3_codon3, Tnuc813-5_codon1, Tnuc813-5_codon2, Tnuc813-5_codon3 = $\mathrm{K} 81 \mathrm{UF}+\mathrm{G}, 28 \mathrm{~S}=\mathrm{TIM}+\mathrm{G}, \mathrm{Cox} 1$ _codon1, EF_codon1 $=\mathrm{TRN}+\mathrm{G}, \mathrm{Cox} 1$ _codon3 = GTR + G, EF_codon3, Tnuc813-1_codon2, Tnuc813-3_codon1 = TVM + G, Nd4toCox1-1_codon1, Nd4toCox1-1_codon2, Nd4toCox1-3_codon1, Nd4toCox1-3_codon3, Tnuc813-1_codon1 = GTR + G, Tnuc813-2, Tnuc813-4= GTR + G, Nd4toCox1-1_codon3, Nd4toCox1-2, Nd4toCox1-3_codon2 $=\mathrm{HKY}+\mathrm{G}$. For the concatenated analyses, the topologies obtained are the same in both methods (ML and BI), as shown in Fig. 2. There is only a small difference in the relationships between the specimens within two of the new species described in the present paper (Cratera tui sp. nov. and C. assu sp. nov.), but without statistical support for any of the two methods. All known species are monophyletic. Three of the new species described here $(C$. tui sp. nov., $C$. imbiri sp. nov. and $C$. paraitinga sp. nov.) form a monophyletic group, which in turn is sister to the species C. cuarassu Carbayo \& Almeida, 2015. Cratera pseudovaginuloides (Riester, 1938) is a sister lineage of C. boja sp. nov., both constituting the sister group of a large clade formed by the species C. assu sp. nov. and C. crioula (Froehlich, 1955) on the one hand and the group constituted by C. picuia, C. arucuia and C. tamoia (Froehlich, 1955). The vast majority of the relationships present high support values at the nodes for both methodologies (PP and bootstrap values) (Fig. 2).

\section{Molecular species delimitation}

Concatenated tree (Fig. 2) provides a summary of the species delimitation results. The ABGD method delimits within the genus Cratera 13 Molecular Operational Taxonomic Units (MOTUs) with a p-value of P 0.001 - 0.0046. The mPTP method delimits 11 candidate species for the ingroup with average support of 0.90. In both delimitations, mPTP and ABGD, C. ochra is delimited as a single candidate species. However, it is not present in the concatenated tree in because there are only COI sequences in GenBank for this species (Table 1 and Suppl Fig. 1). For the same reason, this species $C$. ochra was not included in the BPP analyses.

ABGD predicts a higher number of candidate species than mPTP. Therefore, the ABGD set of candidate species is adopted as a reference to designate the PSHs in order to test as many

Peer] reviewing PDF | (2020:04:48478:1:1:NEW 8 Jul 2020) 
306 scenarios as possible in the validation with the BPP method. The assignment is as follows. All 307 known species are delimited by both ABGD and mPTP methods as candidate species. Hence, 308 each is assigned a PHSs with PSH-4 representing C. cuarassu, PSH-5 being C. crioula, PSH-8 309 being C. tamoia and PSH-10 corresponding to C. pseudovaginuloides. Regarding the rest of 310 Cratera individuals included in this work, the two discovery methods coincide in assigning 311 individuals F2789, MZUSP PL 1051, MZUSP PL 2154, MZUSP PL 2147, MZUSP PL 1014, 312 MZUSP PL 2148 to one candidate species (PSH-1) and individuals MZUSP PL 0458 and 313 MZUSP PL 0459 to another candidate species (PSH-9). Finally, in two cases a clade that mPTP 314 considers as a single MOTU is divided into two candidate species by ABGD that are here 315 designated as candidate species PSH-2, PSH-3, PSH-6 and PSH-7. The species C. picuia and $C$. 316 arucuia are not assigned to any PSH because they are singletons (constituted by a single 317 individual) and thus are not included in the validation step. As a result, 10 PSHs have to be 318 validated in BPP.

319 The species tree resulting from the *BEAST analysis (Fig. 3), used as the input tree to 320 implement the BPP method, differs slightly from the tree inferred using the concatenated dataset. 321 In the ML and BI phylogenies inferred from the concatenated dataset (Fig. 2), the clade formed 322 by PSH-9 and PSH-10 is sister to the clade constituted by PSH-5, PSH-6, PSH-7 and PSH-8. 323 However, in the *BEAST tree PSH-9 + PSH-10form the sister clade of the rest of the species. 324 These small differences could be due to the fact that C. picuia and C. arucuia were not included 325 in the *BEAST analysis, but it does not affect the subsequent species assignment. used in the 4 BPP analyses (M1, M2, M3 and M4) do not have a significant effect on the results of the BPP analyses (Fig. 3), except for the node that separates PSH-2 and PSH-3, the PP value of which is higher than 0.95 in the M2 and M4 models (small ancestral population size) and a little lower than 0.95 in the M1 and M3 models (large ancestral population size). Of the 10 PSHs that are analysed as starting hypotheses for BPP, only 9 are validated since PSH-6 and PSH-7 form a single SSH (SSH-6 in Fig. 3). In conclusion, the BPP results determine the presence of 9 SSHs, validating five new species of Cratera (SSH-1, SSH-2; SSH-3, SSH-6, and SSH-9) that will be described.

\section{Taxonomic account}


337 Order Tricladida Lang, 1884

338 Suborder Continenticola Carranza et al., 1998

339 Family Geoplanidae Stimpson, 1857

340 Genus Cratera Carbayo et al., 2013

341

342 Cratera assu Araujo, Carbayo, Riutort \& Álvarez-Presas, sp. nov.

343 urn:1sid:zoobank.org:act:DE3D812D-C387-40BD-9273-7BC1FE59D09C

344

345 Synonymy.

346 Cratera sp. 1: Carbayo et al. (2013).

347 Etymology. The specific epithet assu means large in Tupi (indigenous Brazilian language;

348 Tibiriçá, 1984). It refers to the large distal dilation of the ejaculatory duct. The specific epithet is 349 invariable.

350 Type locality. Parque Nacional da Serra da Bocaina, São José do Barreiro, State of São Paulo, 351 Brazil.

352 Material examined. All specimens collected in the Parque Nacional da Serra da Bocaina, São

353 José do Barreiro, State of São Paulo, Brazil (-22.75, -44.62) by Carbayo and co-workers

354 Holotype MZUSP PL 2150 (Field code F2825), sexually mature: 8 September 2008. Horizontal

355 sections of pre-pharyngeal region-1 on 5 slides; transverse sections of pre-pharyngeal region-2

356 on 5 slides; sagittal sections of pharynx and copulatory apparatus on 34 slides. Paratypes:

357 MZUSP PL 2146 (Field code F2025), sexually mature: 5 February 2008. Horizontal sections of

358 pre-pharyngeal region-1 on 15 slides; transverse sections of pre-pharyngeal region-2 on 7 slides.

359 Sagittal sections of copulatory apparatus on 15 slides. MZUSP PL 1050 (Field code F2807),

360 sexually mature: 7 September 2008. Transverse sections of cephalic extremity on 7 slides;

361 horizontal sections of ovaries on 5 slides; transverse sections of pre-pharyngeal region on 6

362 slides; sagittal sections of pharynx on 12 slides; sagittal sections of copulatory apparatus on 11

363 slides. MZUSP PL 1052 (Field code F2821), sexually mature: 8 September 2008. Sagittal

364 sections of a piece of the body behind cephalic extremity on 71 slides; sagittal sections of

365 pharynx and copulatory apparatus on 71 slides. MZUSP PL 2151 (Field code F2834): 8

366 September 2008. Preserved in $80 \%$ ethanol.

367 Diagnosis

PeerJ reviewing PDF | (2020:04:48478:1:1:NEW 8 Jul 2020) 
369

370

371

372

373

374

375

376

377

378

379

380

381

382

383

384

385

386

387

388

389

390

391

392

393

394

395

396

397

398

brown to black brown, excepting the yellow orange or grayish body margins. A thin grayish

median stripe may be present. Eyes dorsal. Pharynx bell-shaped. Penis papilla horizontal; distal

portion of ejaculatory duct very widened, occupying most of the of the penis papilla. Common glandular ovovitelline duct absent.

\section{Description}

Live animals ranging between 50-65 $\mathrm{mm}$ in length, and 3.0-3.5 $\mathrm{mm}$ in width $(\mathrm{n}=3)$. Preserved, ranging between $38-53 \mathrm{~mm}$ and $5-7 \mathrm{~mm}$, respectively $(\mathrm{n}=3)$. Body elongate, slightly lanceolated, with maximum width at the level of the pharynx. Anterior to the pharynx, the body narrows gradually towards the rounded anterior tip; posterior to the pharynx, body becomes narrower abruptly near posterior, pointed tip. Dorsum slightly convex, ventral side flattened. Creeping sole as wide as $92-94 \%$ of body width at the pre-pharyngeal region. In holotype, mouth and gonopore at a distance from anterior extremity equal to $70-74 \%$ and $85 \%$ of body length, respectively $(\mathrm{n}=2)$.

Color of the dorsum varies from chestnut brown (Fig. 4A) to black brown (Fig. 4B). A submarginal yellow orange or grayish stripe is present in anterior tenth of the body; posteriorly, this stripe becomes marginal. However, this stripe, measuring $8 \%$ of body width, is inconspicuous in some animals (Fig. 4B). A thin grayish median stripe, $4 \%$ of body width, may also occur (Fig. 4A). Ventral surface varies from sand yellow (Fig. 4A, inset) to light ivory (Fig. 4B, inset).

Each eye is formed by a single pigment cup $25-30 \mu \mathrm{m}$ in diameter. Clear halos around eyes were not observed. Eyes contour anterior extremity of the body in a single row along the anterior $13-16 \%$ of body length $(n=2)$; then they spread onto the dorsum in a lateral band with $1 / 3$ th of the body width on each side, reaching the posterior tip.

Sensory pits, 13-18 $\mu \mathrm{m}$ deep, in a uniserial ventro-lateral row, from very anterior tip extending posteriorly up to $29 \%$ of body length. Dorsal and ventral epidermis in pre-pharyngeal region pierced by necks of two types of gland cells producing erythrophil and cyanophil granules. Rhabditogen cells discharge their content through dorsal epithelium. Glandular margin constituted by two types of gland cells, one abundant type producing xanthophil granules and a less abundant type secreting erythrophil granules.

Cutaneous musculature constituted of a subepidermal circular layer, followed by two 
399 diagonal layers with decussate fibers, and then a strongly developed longitudinal layer with 400 fibers arranged in bundles (Fig. 4C). Longitudinal layer thickness ranging between 40-62.5 $\mu \mathrm{m}$ $401 \quad(\mathrm{n}=4)$ dorsally, and 40-90 $\mu \mathrm{m}$ ventrally; dorsally, fibers gathered into well-delimited and more 402 compact bundles than ventrally. Thickness of cutaneous muscle coat ranging between $8.9 \%$ $403 \quad 13.4 \%(\mathrm{n}=4)$.

404

405 406 407 408 409 410 411 412 413 414 415
Three parenchymal muscle layers throughout the body: a dorsal layer of diagonal decussate fibers (20-21 $\mu$ m thick; $n=2)$, a transverse supraintestinal layer $(145-157 \mu \mathrm{m}, \mathrm{n}=2)$, and a transverse subintestinal one $(90 \mu \mathrm{m} ; \mathrm{n}=2)$. Central nervous system as a ventral nerve plate. Cerebral ganglia were not discerned.

Mouth located shortly behind middle of pharyngeal pouch. Pharynx bell-shaped, with dorsal insertion posterior to the ventral one about $40 \%$ of pharyngeal length ( $n=2$; Fig. 4D). Esophagus length, $33 \%$ of pharyngeal length $(\mathrm{n}=2)$. Outer pharyngeal epithelium underlain by a one-fiber-thick layer of longitudinal muscle, followed by a circular one (6-10 $\mu \mathrm{m}$ thick; $\mathrm{n}=3)$; inner epithelium underlain by a layer $(70-150 \mu \mathrm{m} ; \mathrm{n}=3)$ of circular fibers with interspersed longitudinal fibers, followed by a longitudinal muscle layer $(9-10 \mu \mathrm{m} ; \mathrm{n}=3)$. Pharyngeal pouch 1.6-2.6 $\mathrm{mm}$ anterior to prostatic vesicle $(\mathrm{n}=2)$.

Testes dorsal, located under the supraintestinal transverse muscle layer, partially placed between the intestinal diverticula (Fig. 4C). Sperm ducts run immediately above the subintestinal muscle layer, dorso-medially to the ovovitelline ducts (Fig. 4C). Each sperm duct communicates with the respective short diverticulum projected from the proximal, slightly widened section of the prostatic vesicle. The prostatic vesicle exhibits an inverted U-shaped loop before penetrating the penis bulb and communicating with the ejaculatory duct (Fig. 5A). Prostatic vesicle lined with a ciliated, tall epithelium, the free surface of it is irregular. This epithelium is traversed by cells producing fine erythrophil granules. Prostatic vesicle surrounded by a $15-33-\mu \mathrm{m}$ thick $(\mathrm{n}=4)$ circular muscle layer. Proximal portion of the ejaculatory duct slightly sinuous. At the basis of the penis papilla, ejaculatory duct widens to form a very large cavity (Figs. 5A-C). At the tip of penis papilla this cavity narrows to open into male atrium. Ejaculatory duct lined with a cuboidal, ciliated epithelium and surrounded by a $10-25-\mu \mathrm{m}$ thick circular muscle, followed by an additional, one-fiber-thick longitudinal muscle $(n=3)$.

Penis papilla a long, more or less conical, protrusible organ extending along the length of the male atrium or even beyond (Fig. 5A-C). Lining epithelium of the widened portion of the 
430 ejaculatory duct cuboidal, not ciliated, pierced by necks of cell producing minute erythrophil 431 granules $(<0.2 \mu \mathrm{m})$, and underlain by a layer $(20-28 \mu \mathrm{m} ; \mathrm{n}=2)$ of circular muscle, followed by a 432 simple layer of longitudinal muscle. The penis papilla is clothed with a cuboidal, non-ciliated 433 epithelium, which is traversed by necks of cells producing erythrophil granules and is underlain 434 by a $20-\mu$ m-thick layer of circular muscle $(n=3)$ with some interspersed longitudinal fibers. 435 Male atrium ample and smooth, not narrowed distally. It is lined with a cuboidal, non436 ciliated epithelium, which is pierced by necks of cells producing granules with weak xanthophil affinity. Male atrial epithelium underlain by a muscle layer $(18-45 \mu \mathrm{m} ; \mathrm{n}=3)$ of circular fibers.

Vitellaria well developed. Ovaries mature, more or less ovoid, with maximum length ranging between 400-440 $\mu \mathrm{m}$ antero-posteriorly $(\mathrm{n}=2)$. They are located immediately above the ventral nerve plate, at a distance from anterior tip equivalent to $21 \%$ of body length. Ovovitelline ducts arise from external side of the ovaries, whereafter they run backwards above ventral nerve plate. The ducts ascend laterally to the female atrium, posteriorly and medially inclined, to unite dorsally to the atrium (Fig. 5A). Half of the ascending portion of these ducts receives secretion of shell glands (Fig. 5A). Ovovitelline ducts open into the female genital canal. Common glandular ovovitelline duct absent. The female canal is a long forwards directed canalicular projection of the posterior portion of the female atrium (Fig. 5D). Female atrium, as long as male atrium, and funnel-shaped. Lateral walls of female atrium partially occlude its lumen. Its lining epithelium is columnar with the free surfaces of the cells being erythrophil and provided with small recesses 449 (Fig. 5D).

In the anterior portion of female atrium, the epithelium is $25-40 \mu \mathrm{m}$ high $(\mathrm{n}=3)$; posteriorly it becomes taller and its nuclei arranged at different heights within the cells, thus giving the epithelium a multilayered aspect. Necks of cells producing erythrophil granules pierce this epithelium, which is underlain by two layers of muscles; the anterior half of the atrium is surrounded by a $5-\mu \mathrm{m}$-thick circular muscle followed by a $3-\mu \mathrm{m}$-thick longitudinal one $(\mathrm{n}=3)$. Arrangement of these layers is inverted on the posterior half of the female atrium, i. e., a layer (5-7 $\mu \mathrm{m})$ of longitudinal muscles is followed by a layer $(12-20 \mu \mathrm{m})$ of circular fibers $(\mathrm{n}=3)$.

\section{Discussion}

Regarding the external aspect, C. cryptolineata Rossi \& Leal-Zanchet, 2017 is the only species of the genus similar to C. assu in that both species display a uniform dark dorsum with clear margins. However, their copulatory apparatuses are notably different from each other in 
461 that in $C$. assu the distal, widened portion of the ejaculatory duct is much larger, occupying most 462 of the penis papilla. This remarkable trait is also shared with C. cuarassu, but in this latter 463 species the penis papilla is vertically oriented (vs. horizontally in C. assu). The molecular 464 delimitation methods all clearly point to $C$. assu being a species differentiated from the rest of 465 species molecularly analysed in the present study. On the other hand, although the primary 466 hypothesis pointed that this lineage could be divided into two species (ABGD analysis), neither 467 the molecular validation nor the morphological analysis found evidence of this possibility.

\section{Cratera boja Araujo, Carbayo, Riutort \& Álvarez-Presas, sp. nov.}

470

urn:1sid:zoobank.org:act:46D76DD7-B129-461D-8803-3E918AA4601C

471

472 Etymology. The specific epithet boja means intermediate, middle in Tupi (Tibiriçá, 1984). It

473

474

475

476

477

478

479

480

481

482

483

484

485

486

487

488

489

490

491 refers to intermediate size of the distal dilation of the ejaculatory duct. The specific epithet is invariable.

Type locality. Parque Nacional da Serra da Bocaina, São José do Barreiro, State of São Paulo, Brazil.

Material examined. All specimens collected in Parque Nacional da Serra da Bocaina, São José do Barreiro, State of São Paulo, Brazil (-22.75, -44.62), in September 2008 by Carbayo and coworkers. Holotype MZUSP PL 0459 (Field code F2829), sexually mature: transverse sections of cephalic extremity on 4 slides; horizontal sections of a portion of the body behind cephalic extremity on 4 slides; transverse sections of pre-pharyngeal portion on 7 slides; sagittal sections of pharynx on 6 slides; sagittal sections of copulatory apparatus on 5 slides (of which one slide was lost). MZUSP PL 0458 (Field code F2828), incompletely mature: horizontal sections of a portion behind anterior extremity on 6 slides; transverse sections of the pre-pharyngeal portion on 22 slides; sagittal sections of pharynx on 13 slides; sagittal sections of copulatory apparatus on 14 slides.

\section{Diagnosis}

Species of Cratera $34 \mathrm{~mm}$ long preserved; dorsum olive grey with large black patches, being more concentrated in paramedian bands; eyes marginal; pharynx bell-shaped; distal portion of ejaculatory duct widened to occupy half of the penis papilla; male atrium separated from female atrium by a narrowing; penis papilla shorter than male atrium; prostatic vesicle with

PeerJ reviewing PDF | (2020:04:48478:1:1:NEW 8 Jul 2020) 
492 inverted-U shape in lateral view; penis papilla postero-dorsally oriented; numerous cyanophil 493 cell necks piercing roof of male atrium; female atrium half the length of the male atrium; 494 common glandular ovovitelline duct absent.

\section{Description}

496

497

498

499

500

501

502

503

504

505

506

507

508

509

510

511

512

513

514

515

516

517

518

519

520

521

522

Preserved holotype $34 \mathrm{~mm}$ in length and $4 \mathrm{~mm}$ in width. Paratype was measured only in its width, $4.5 \mathrm{~mm}$. Body elongate, with nearly parallel margins along most of body length. Anterior extremity rounded; posterior pointed. Dorsal side convex; ventral side flattened. Creeping sole, $92-95 \%$ of body width at the pre-pharyngeal region. Mouth at a distance from anterior extremity equal to $71 \%$ of body length; gonopore at $87 \%$ (holotype).

Dorsum spotted black on olive grey ground color (Fig. 6A-D). Large black patches join each other. Patches distributed all over dorsum and especially concentrated in a median band (33\% of body width). This band may be divided by a thin midline, measuring $6 \%$ of body width (Fig. 6C). Ventral surface olive gray (Fig. 6A), gray at anterior extremity.

Each eye is formed by a single pigmented cup $32-40 \mu \mathrm{m}$ in diameter. Clear halos around eyes absent. Eyes contour anterior extremity in a single row, posteriorly eye cups are arranged marginally in 1-3 rows up to the posterior tip of the body.

Sensory pits were not found despite intensive search on the sections, albeit that these are partially damaged. Dorsal and ventral epidermis in pre-pharyngeal region pierced by necks of two types of gland cells producing erythrophil and cyanophil granules, respectively.

Furthermore, rhabditogen cells discharge their content through dorsal epithelium and, much more rarely, through the ventral epithelium as well. Glandular margin not well defined (Fig. 7A), constituted by three types of gland cells, one abundant type producing xanthophil granules and a less abundant type secreting erythrophil granules, and rhabditogen cells.

Cutaneous musculature constituted of a subepidermal circular layer, followed by two diagonal layers with decussate fibers, and an inner, strongly developed longitudinal layer with fibers arranged in bundles (Fig. 7A). Longitudinal layer $55 \mu \mathrm{m}$ thick dorsally and $90 \mu \mathrm{m}$ ventrally. Dorsal fibers of this layer are gathered into well-delimited and more compact bundles than ventrally. Thickness of cutaneous muscle coat, $12.5 \%$ of body height (holotype).

Three parenchymal muscle layers throughout the body: a dorsal layer of diagonal decussate fibers ( $20 \mu \mathrm{m}$ thick, holotype), a transverse supraintestinal layer $(60 \mu \mathrm{m})$, and a transverse subintestinal one $(70 \mu \mathrm{m})$. Central nervous system as a ventral nerve plate. Cerebral 
523 ganglia more or less $5 \mathrm{~mm}$ long, starting at $0.5 \mathrm{~mm}$ from anterior extremity (1.5\% of body 524 length, holotype).

$525 \quad$ Mouth located at the end of second third of pharyngeal pouch (Fig. 7B). Pharynx bell-

526 shaped, with dorsal insertion posterior to the ventral one at the equivalent of $36 \%$ of pharyngeal 527 length $(\mathrm{n}=2)$. Esophagus length, $21 \%$ of pharyngeal length $(\mathrm{n}=2)$. Outer pharyngeal epithelium 528 underlain by a one-fiber-thick longitudinal muscle layer followed by a circular one ( $4 \mu \mathrm{m}$ thick; $529 \mathrm{n}=2)$; inner epithelium underlain by a circular muscle layer (22-60 $\mu$ m thick; $n=2)$, followed by a 530 longitudinal $(5 \mu \mathrm{m} ; \mathrm{n}=2)$. Pharyngeal pouch of holotype $2.75 \mathrm{~mm}$ anterior to prostatic vesicle. Testes dorsal, located under the supraintestinal transverse muscle layer, partially placed

532 between the intestinal diverticula (Fig. 7A). Posteriormost testes lateral to ventral insertion of the 533 pharynx. Sperm ducts run immediately above the subintestinal muscle layer, dorso-medially to 534 the ovovitelline ducts (Fig. 7A). Below prostatic vesicle, sperm ducts curve medially and 535 anteriorly, to communicate separately with the respective short lateral diverticula of the extrabulbar and tubular prostatic vesicle (Fig. 7C, D). In lateral view, the latter has the shape of an inverted U. Prostatic vesicle approaches anterior region of penis bulb to communicate with 538 ejaculatory duct.

Prostatic vesicle lined with a ciliated, columnar epithelium, traversed by necks of two 540 types of gland cells producing erythrophil and cyanophil granules, respectively; the cyanophil 541 glands are much more abundant (Fig. 8A). Prostatic vesicle surrounded by a $130-\mu \mathrm{m}$-thick

542 circular muscle layer. Proximal portion of ejaculatory duct sinuous; distal portion straight, 543 traversing center of penis papilla; midway of penis papilla, ejaculatory duct widens to give rise to 544 a relatively large, funnel-shaped cavity, which opens at the tip of the penis papilla (Fig. 7C-D, 545 8A). Ejaculatory duct lined with a cuboidal, ciliated epithelium, which at its dilated portion is 546 pierced by necks of cells producing xanthophil granules. Ejaculatory duct surrounded by a 20$547 \mu \mathrm{m}$ thick circular muscle layer.

Penis papilla more or less conical, 1.3-1.5 times longer than its diameter and as long as 549 the male atrium or shorter (Fig. 7C-D, 8A). Penis papilla clothed with non-ciliated epithelium. 550 Columnar epithelium lines basal half of papilla; cuboidal epithelium lines distal half. Epithelium 551 of papilla pierced by necks of three types of cells producing erythrophil, xanthophil and 552 cyanophil granules, respectively (but the latter appears erythrophil in paratype); necks of 553 cyanophil glands only piercing epithelium of basal half of penis papilla. Epithelium of penis 
554 papilla underlain by a $8-10-\mu \mathrm{m}$-thick layer of circular muscle fibers, followed by a longitudinal

555 layer, $10-\mu \mathrm{m}$ thick. Parenchyma of penis papilla richly traversed by intermingled circular and 556 longitudinal muscle fibers.

$557 \quad$ Male atrium ample and smooth, lined with a columnar, non-ciliated epithelium.

558 Epithelium clothing roof of male atrium pierced by very numerous necks of cells producing 559 cyanophil granules. Ventral portion of male atrium pierced by less numerous necks of glands 560 producing erythrophil granules. Atrial epithelium underlain by a subepithelial layer (10-12 $\mu \mathrm{m}$ 561 thick) of circular muscle fibers, followed under dorsal epithelium by a 3-5- $\mu \mathrm{m}$-thick longitudinal 562 muscle layer.

563 Vitellaria well developed. Ovaries were not found in histological sections and were 564 probably destroyed in the portion from which a tissue sample was extracted. Ovovitelline ducts 565 well developed, having their lumen well defined. They ascend laterally to proximal portion of the 566 female atrium, posteriorly and medially inclined. Subsequently, the ducts unite dorsally to the 567 posterior portion of atrium. Distal half of ascending portion of these ducts receives shell glands.

568 Ovovitelline ducts open into female genital canal, i.e., a common glandular ovovitelline duct 569 being absent (see 'co' in Fig. 7 C,D). Female genital canal projects forwards from the postero570 dorsal portion of the female atrium. Female atrium ample, 55-57\% the length of male atrium and 571 lined with 30-70 $\mu \mathrm{m}$ high, non-ciliated epithelium, with stratified aspect (Fig. 8. A-C). Surface of 572 epithelium sinuous; subapical portion of epithelial cells cyanophil (Fig. 8B) or erythrophil (Fig.

573 8C). Necks of two types of cells, producing erythrophil and cyanophil granules, respectively, 574 pierce the atrial epithelium, which is underlain by a $18-26-\mu \mathrm{m}$ thick and dense layer of circular 575 muscle, followed by a 3-4- $\mu$ m thick longitudinal muscle layer.

\section{Discussion}

$577 \quad$ C. boja is distinctive among all species of the genus in the spotted color pattern of the 578 dorsal side. Regarding its copulatory apparatus, there are five species with a similar aspect of the 579 copulatory apparatus and size of the dilation of the ejaculatory duct, namely, C. aureomaculata 580 Rossi \& Leal-Zanchet, 2017, C. nigrimarginata Rossi \& Leal-Zanchet, 2017, C. pseudovaginuloides, C. tamoia, and C. viridimaculata Negrete \& Brusa, 2016. However, (a) all 582 of these five species have a common glandular ovovitelline duct (absent in C. boja; but see 583 redescription of C. pseudovaginuloides in Riester, 1938); (b) the male and female atria are not 584 separated by a constriction in C. pseudovaginuloides (separated in C. boja); (c) the penis papilla 
585 is longer than the male atrium in C. nigrimarginata and C. pseudovaginuloides (shorter in $C$.

586 boja); (d) the prostatic vesicle is horizontal in C. nigrimarginata (inverted-U shaped in C. assu);

587 (e) the female atrium is funnel-shaped, and its posterior section oriented upwards in $C$.

588 viridimaculata (horizontal, and not funnel-shaped in C. boja); (f) the prostatic vesicle runs

589 postero-dorsally in C. aureomaculata and C. tamoia (inverted U-shaped in C. boja); (g) the penis

590 papilla exhibits a postero-ventral orientation in C. tamoia (postero-dorsal in C. boja); and (h)

591 there is no accumulation of necks of cyanophil cells piercing the roof of the male atrium in $C$.

592 nigrimarginata, C. pseudovaginuloides, and C. tamoia (cell necks present in C. boja).

593 The phylogenetic tree as well as the molecular species delimitation analyses also show

594 that this species is distinct and well-delimited from C. pseudovaginuloides and C. tamoia, the

595 two species included in these analyses that show similarities with C. boja.

596

597 Cratera tui Araujo, Carbayo, Riutort \& Álvarez-Presas, sp. nov.

598 urn:1sid:zoobank.org:act:FB96BE96-86AD-41FB-961F-C0337C56A596

599

600 Synonymy. Cratera sp. 4: Carbayo et al. (2013).

601

602 Etymology. The specific epithet tui means tiny, insignificant in Tupi (Tibiriçá, 1984). It refers to 603 the small distal dilation of the ejaculatory duct. The specific epithet is invariable.

604 Type locality. Parque Nacional da Serra da Bocaina, São José do Barreiro, State of São Paulo, 605 Brazil.

606 Distribution. Parque Nacional da Serra da Bocaina, São José do Barreiro, State of São Paulo;

607 Parque Nacional Itatiaia, Resende, State of Rio de Janeiro, Brazil.

608 Material examined. Holotype MZUSP PL 1051 (Field code F2809), sexually mature: Parque

609 Nacional da Serra da Bocaina, São José do Barreiro, State of São Paulo (-22.75, -44.62). coll. F.

610 Carbayo and co-workers, 7 September 2008; transverse sections of cephalic extremity on 4

611 slides; sagittal sections of a portion immediately behind cephalic extremity on 19 slides;

612 horizontal sections of a immediately behind on 12 slides; transverse sections of pre-pharyngeal

613 on 16 slides; transverse sections of pharynx on 17 slides; sagittal sections of copulatory

614 apparatus on 23 slides. Paratypes: MZUSP PL 1014 (Field code F2031), incompletely mature:

615 Ibidem, 7 September 2008; sagittal sections of copulatory apparatus on 6 slides. MZUSP PL 
6162148 (Field code F2054), incompletely mature: Ibidem, 9 September 2008, sagittal sections of 617 pharynx and copulatory apparatus on 13 slides (of which 3 slides were lost). MZUSP PL 2147 618 (Field code F2040), juvenile: Ibidem, 9 February 2007, preserved in $80 \%$ ethanol. MZUSP PL 6192149 (Field code F2798): Ibidem, 7 September 2008; preserved in 80\% ethanol. MZUSP PL 6202154 (Field code F5178), incompletely mature: Parque Nacional de Itatiaia, Resende, State of 621 Rio de Janeiro (-22.43328, -44.61539), Brazil, coll. F. Carbayo and co-workers, 5 April 2012, 622 horizontal sections of a body portion behind cephalic extremity on 7 slides; transverse sections of 623 pre-pharyngeal region on 15 slides; sagittal sections of pharynx and copulatory apparatus on 30 624 slides.

\section{Diagnosis}

Species of Cratera 45-70 mm long in preserved condition; dorsum with a melon yellow median stripe, bordered on either side by a jet-black stripe external to which a marginal traffic

628

629

630

631

632

633

634

635

636

637

638

639

640

641

642

643

644

645

646 white stripe; body margins jet black. Anterior $1 / 5$ th of the body colored with a gradient of carmine red; eyes marginal; pharynx cylindrical; pharyngeal pouch $0.6 \mathrm{~mm}$ anterior to the prostatic vesicle (equal to $1 \%$ of body length); penis papilla shorter than male atrium; distal dilatation of ejaculatory duct relatively small; female atrium 2.5 times longer than the male atrium; common glandular ovovitelline duct long.

\section{Description}

The longest and only mature animal (holotype) measured $58 \mathrm{~mm}$ in length, and $7 \mathrm{~mm}$ in width. Body slightly lanceolate, with maximum width at the level of the pharynx. Anterior to the pharynx, narrows gradually towards the rounded tip; posterior to the level of the pharynx, body narrows abruptly close to posterior tip. Dorsum slightly convex, ventral side flattened. Creeping sole $90-95 \%$ of body width at pre-pharyngeal region $(n=2)$. Mouth at a distance from anterior extremity equal to $73 \%$ of body length; the gonopore at $82 \%$ (holotype).

Dorsum with a melon yellow median stripe, $28 \%$ of body width, which is bordered on either side by a jet black stripe, $22 \%$ of the body width (Fig. 9A-B). External to jet black stripes, a traffic white marginal stripe, $10 \%$ of body width; body margin (3\% of the body width) jet black. Anterior $1 / 5$ th of the body colored with a gradient of carmine red, dorsally and ventrally; otherwise, ventral side grey white (Fig. 9B).

Each eye is formed by a single pigmented cup with 33-35 $\mu \mathrm{m}$ in diameter. No clear halos around eyes. Eyes contour the anterior extremity in a single row and run along body margin until 
647 posterior tip.

648 Sensory pits, $19-20 \mu \mathrm{m}$ deep, as a uniserial ventro-lateral row, from anterior extremity

649 extending backwards to at least 9\% of body length (holotype). Rhabditogen cells, and necks of

650 two types of gland cells, producing xanthophil and erythrophil granules, respectively, pierce pre-

651 pharyngeal dorsal epithelium; the latter gland cells also pierce ventral epithelium. Conspicuous

652 glandular margin constituted by abundant glands producing erythrophil granules (Fig. 10A).

653 Cutaneous musculature consisting of three layers: a subepidermal circular layer, followed

654 by two diagonals with decussate fibers, and a subjacent longitudinal one, the latter 30-40 $\mu \mathrm{m}$

655 thick dorsally and 40-65 $\mu \mathrm{m}$ thick ventrally $(\mathrm{n}=2)$. Fibers of the longitudinal layer gathered in

656 bundles, which are dorsally better delimited than ventrally. Relative thickness of cutaneous

657 muscle coat, $9.1-12.7 \%(n=2)$.

658 Three parenchymal muscle layers throughout the body, all constituted by fibers relatively

659 densely packed: a dorsal layer of diagonal decussate fibers (15 $\mu \mathrm{m}$ thick, holotype), a transverse

660 supraintestinal layer $(25 \mu \mathrm{m})$, and a transverse subintestinal one $(25 \mu \mathrm{m})$. In paratype MZUSP

661 PL 2154, these layers measured, $20 \mu \mathrm{m}, 72 \mu \mathrm{m}$, and $63 \mu \mathrm{m}$, respectively.

662 Central nervous system as a ventral nerve plate. Clearly evident cerebral ganglia were not

663 found.

664 Mouth in middle of pharyngeal pouch (n=2) (Fig. 10B). Pharynx cylindrical, with dorsal

665 insertion posterior to the ventral one at the equivalent of $20 \%$ of pharyngeal length $(n=2)$.

666 Esophagus length, ranging between 10-20\% of pharyngeal length. Outer pharyngeal epithelium

667 underlain by a one-fiber-thick layer (3-4 $\mu \mathrm{m})$ of longitudinal muscle fibers, followed by a layer

668 of circular fibers $(7-8 \mu \mathrm{m})$; inner pharyngeal epithelium underlain by a layer $(80-100 \mu \mathrm{m})$ of

669 circular fibers, followed by a layer $(10 \mu \mathrm{m})$ of longitudinal fibers $(n=2)$. Pharyngeal pouch 0.2 -

$6701.0 \mathrm{~mm}$ anterior to the prostatic vesicle $(\mathrm{n}=4 ; 0.75 \mathrm{~mm}$ in holotype).

671 Testes mature, dorsal, located under supraintestinal transverse muscle layer, partially

672 placed between the intestinal diverticula. The testes extend from level of ovaries to nearly root of

673 pharynx. Sperm ducts communicate with the respective lateral branches of the prostatic vesicle

674 (Fig. 11A). Paired portion of the prostatic vesicle represents ca. half of the total length of this

675 vesicle. Extrabulbar prostatic vesicle more or less pear-shaped in lateral view, with posterior

676 portion running posteriorly and upwards until anterior region of penis bulb. Vesicle lined with a

677 columnar, ciliated epithelium, which is pierced by necks of cells producing fine erythrophil 
678 granules. A $20 \mu \mathrm{m}$ thick layer of circular muscle fibers surrounds vesicle. Inside penis papilla 679 vesicle communicates with a horizontal, initially sinuous ejaculatory duct which is lined with a 680 cuboidal, ciliated epithelium. Ejaculatory duct surrounded by a $5 \mu \mathrm{m}$ thick layer of circular 681 muscle fibers. Near tip of penis papilla, lumen of the ejaculatory duct doubles its width to form a 682 small cavity (Fig. 11A-C).

683 Penis papilla short, conical and blunt, horizontally oriented; shorter than male atrium

684 (Fig. 11A-B). Male atrium slightly folded in its proximal region. Penis papilla and male atrium 685 clothed with a cuboidal non-ciliated epithelium, pierced by necks of two types of cells, 686 producing erythrophil and xanthophil granules, respectively. Epithelium of penis papilla and that 687 of male atrium underlain by a $7-\mu \mathrm{m}$-thick layer of circular muscle fibers, followed by a $7-\mu \mathrm{m}$ -

688

689

690

691

692

693

694

695

696

697

698

699

700

701

702

703

704

705

706

707

708 thick layer of longitudinal muscle fibers.

Vitellaria well developed. Ovaries elongate, more or less ovoid, measuring $250 \mu \mathrm{m}$ in antero-posterior direction. They are located immediately above the ventral nerve plate, at a distance from anterior tip equivalent to $30 \%$ of body length. Ovovitelline ducts arise from dorsolateral side of ovaries and run backwards above the ventral nerve plate. They ascend laterally to female atrium to unite dorsally to female atrium to form common glandular ovovitelline duct (Fig. 11A). Distal ascending portion of oviducts receiving shell glands. Common glandular ovovitelline duct long (1.2 mm, i.e., 1/3th of the length of female atrium in holotype), communicating with female genital canal, the latter being a projection of the posterior portion of female atrium directed forwards and dorsally. Female atrium funnel-shaped, with a length 2.5 times that of male atrium. Lateral wall of female atrium with folds narrowing its lumen. Female atrium lined with a non-ciliated, $25 \mu \mathrm{m}$ tall epithelium along anterior $4 / 5$ th of its length.

Posterior $1 / 5$ th lined with a $50-\mu \mathrm{m}$-high epithelium that might display a multilayered aspect; quality of the sections precluded confirmation. Necks of cells producing erythrophil granules pierce female epithelium, which is underlain by a layer of circular muscle fibers ( $7 \mu \mathrm{m}$ thick, holotype), followed by a layer of longitudinal fibers ( $7 \mu \mathrm{m}$ thick).

\section{Discussion}

Among all species of the genus, only C. taxiarcha (Marcus, 1951) resembles C. tui in the three-color striped pattern of the dorsum, composed of white, yellow, and black colors. However, in C. taxiarcha, the median stripe is white (vs. yellowish in C. tui). Regarding the copulatory apparatus, all species in the genus possess a female atrium as long as the male atrium, with minor 
709 variations, whereas in C. tui it is 2.5 times longer. The molecular delimitation methods all clearly

710 point to $C$. tui being a species differentiated from the rest of species molecularly analysed in the

711 present study.

712

713 Cratera imbiri Araujo, Carbayo, Riutort \& Álvarez-Presas, sp. nov.

714 urn:lsid:zoobank.org:act:CC5B22EB-9E7C-490F-A6FF-03757BA03C26

715

716 Etymology. The name imbiri refers to Vila de São Matheus do Imbiri, former name of Campos

717 do Jordão, type locality of the species. The specific epithet is invariable.

718 Type locality. Parque Estadual Campos do Jordão, Campos do Jordão, State of São Paulo, 719 Brazil.

720 Distribution. Only known from the type locality.

721 Material examined. Holotype MZUSP PL 2155 (Field code F5512), sexually mature: Parque

722 Estadual Campos do Jordão, Campos do Jordão, State of São Paulo, Brazil (-22.68878, -

723 45.48068). coll. F. Carbayo and co-workers, 15 November 2012. Horizontal sections of a body

724 portion behind cephalic extremity on 7 slides; transverse sections of pre-pharyngeal region on 9

725 slides; sagittal sections of pharynx on 13 slides; sagittal sections of copulatory apparatus on 9

726 slides.

727 Diagnosis

728 Species of Cratera $26 \mathrm{~mm}$ long in preserved condition; dorsal median stripe sulfur

729 yellow, bordered on either side by a khaki grey band; body margins cream; in anterior 1/4th of

730 the body, this pattern covered with a color gradient of coral red; eyes marginal; pharynx

731 cylindrical, with dorsal insertion posteriorly shifted at the equivalent of $20 \%$ the length of

732 pharynx; pharyngeal pouch very close to prostatic vesicle; paired portion of the prostatic vesicle

733 with 1/3th of total length of this organ; epithelium of penis papilla underlain by a layer of

734 circular muscle fibers; female atrium 3.2 times longer than male atrium; female atrium narrows

735 gradually towards its posterior section; common glandular ovovitelline duct long.

736

737

738

739

\section{Description}

When creeping, body $38 \mathrm{~mm}$ long and $2.5 \mathrm{~mm}$ wide. Preserved $26 \mathrm{~mm}$ and $4 \mathrm{~mm}$, respectively. Body margins parallel along most of its length. Extremities of the body rounded. The dorsum slightly convex, ventral side flattened. Creeping sole, $94 \%$ of body width at the pre- 
740 pharyngeal region. Mouth at a distance from anterior extremity equal to $70 \%$ of body length;

741 gonopore, $78 \%$.

742 Dorsal color with a sulfur yellow median stripe, $14 \%$ of the body width, this bordered on

743 either side by a khaki grey band, $34 \%$ of the body width. Body margins ( $9 \%$ of body width)

744 cream (Fig. 12A). In anterior $1 / 4$ th of body, this pattern covered with a gradient color of coral

745 red. Ventral side coral red along anterior 1/4th, and cream colored behind (Fig. 12B).

746 Each eye is formed by a single pigment cup 22-25 $\mu \mathrm{m}$ in diameter. No clear halos around

747 eyes were observed. Eyes contour the anterior extremity in a single row and extend marginally

748 until posterior extremity. Anteriormost region of the body, with $3 \mathrm{~mm}$ in length, was not

749 available for histological examination since it was degraded for DNA extraction. Sensory pits,

$750 \quad 18-20 \mu \mathrm{m}$ deep, as a uniserial ventro-lateral row extending backwards along a body $3.7 \mathrm{~mm}$ of

751 the body. Necks of gland cells producing erythrophil granules pierce dorsal and ventral

752 epithelium in pre-pharyngeal region. In addition, rhabditogen cells discharge their content

753 through dorsal epithelium. Glandular margin constituted of abundant glands producing

754 erythrophil granules.

755 Cutaneous musculature formed by a subepidermal circular muscle, followed by two

756 diagonals with decussate fibers, and a subjacent longitudinal muscle one, $35 \mu \mathrm{m}$ thick dorsally

757 and $30 \mu \mathrm{m}$ thick ventrally. Thickness of cutaneous muscle coat, $11.3 \%$ of body height in the pre-

758 pharyngeal region.

759 Three parenchymal muscle layers are present throughout the body: a dorsal layer of

760 diagonal decussate fibers (10-13 $\mu \mathrm{m}$ thick), a transverse supraintestinal layer (18-24 $\mu \mathrm{m})$, and a

761 transverse subintestinal one $(20-23 \mu \mathrm{m})$.

762 Central nervous system as a ventral nerve plate. Cerebral ganglia not discerned.

763 Mouth located at the end of the anterior half of pharyngeal pouch (Fig. 12C). Pharynx

764 cylindrical, with dorsal insertion posterior to the ventral one at the equivalent of $7 \%$ of

765 pharyngeal length. Esophagus length $20 \%$ of pharyngeal length. Outer pharyngeal epithelium

766 underlain by a one-fiber-thick layer of longitudinal muscle fibers, followed by a layer of circular

767 fibers ( $5 \mu \mathrm{m}$ thick); inner pharyngeal epithelium underlain by a well-developed layer of circular

768 muscle fibers $(60-100 \mu \mathrm{m})$, followed by a thinner layer of longitudinal fibers $(8-9 \mu \mathrm{m})$.

769 Pharyngeal pouch $80 \mu \mathrm{m}$ anterior to prostatic vesicle.

770

Testes mature, dorsal, located under the supraintestinal transverse muscle layer, partially 
771 placed between the intestinal diverticula. The testes extend from $200 \mu \mathrm{m}$ behind the level of the

772 ovaries to $1 \mathrm{~mm}$ anterior to the root of pharynx. Sperm ducts highly constricted at the point of 773 communication with the respective branches of prostatic vesicle. Paired portion of this vesicle

774 occupies ca. 1/3rd of the total length of the organ. Prostatic vesicle extrabulbar, running postero-

775 dorsally until anterior region of penis bulb. Vesicle lined with a columnar, ciliated epithelium,

776 which is pierced by necks of cells producing fine erythrophil granules. A coat of $50-\mu \mathrm{m}$-thick

777 circular muscles surrounds the vesicle. Inside the penis papilla, vesicle communicates with the

778 horizontal ejaculatory duct, which is sinuous proximally. This duct is widened distally at the tip

779 of the penis papilla at the equivalent of $2 / 5$ th of length of penis papilla. Ejaculatory duct lined

780 with a cuboidal, ciliated epithelium, its cilia being as long as cell height, i.e., $10 \mu \mathrm{m}$. Ejaculatory

781 duct surrounded by a 5 - $\mu$ m-thick layer of circular muscle fibers.

782 Cylindrical penis papilla short, horizontally orientated, with rounded tip; it is shorter than

783 male atrium (Fig. 13A-C). Male atrium as long as 1.2 its height, with smooth folds. A large,

784 transverse, annular fold strongly narrows communication with female atrium (Fig. 13A, C).

785 Penis papilla and male atrium clothed with a cuboidal-to-columnar, non-ciliated epithelium; the

786 subapical portion of its cells bieng xanthophil. Papillar epithelium pierced by necks two types of

787 cells producing granules, one erythrophil, another weakly basophil. Additionally, cells with gross

788 necks (6 $\mu \mathrm{m}$ in diameter) and erythrophil amorphous appearance are located immediately under

789 the epithelium. Epithelium of penis papilla and that of male atrium underlain by a $6-\mu \mathrm{m}$-thick

790 layer of circular muscle fibers.

$791 \quad$ Vitellaria well developed. Ovaries ellipsoid, measuring $450 \mu \mathrm{m}$ in diameter in antero-

792 posterior direction (Fig. 13D), located immediately above the ventral nerve plate, at a distance

793 from anterior tip equivalent to $21 \%$ of body length. Ovovitelline ducts arise from dorso-lateral

794 wall of ovaries, subsequently run backwards above the ventral nerve plate. Oviducts ascend

795 laterally to the female atrium to unite dorsally to the mid-portion of the female atrium to form the

796 common glandular ovovitelline duct (Fig. 13A). The distal half, ascending portion of the ducts

797 receives the openings of shell glands. The common glandular ovovitelline duct is about $0.9 \mathrm{~mm}$

798 long (47\% of the length of female atrium), and communicates with the female genital canal. This

799 canal is a projection of the postero-dorsal portion of the female atrium and is forwards and

800 dorsally directed. Female atrium 3.2x the length of male atrium. Posterior third of female atrium

801 with lateral folds narrowing its lumen. Female atrium lined with a non-ciliated, $20 \mu \mathrm{m}$ tall 
802 epithelium along anterior $3 / 4$ of its length. Gland cells producing erythrophil granules discharge

803 their secretion into female atrium, which seems to be underlain by two muscle layers.

804 Discussion

805 This small species displays a color pattern that cannot be confounded with any of its 806 congeners. Regarding the internal morphology, only C. tui resembles C. imbiri in that both 807 species have an uncommonly long female atrium, at least 2.5 times longer than the male one.

808 Indeed, C. tui and C. imbiri are very similar in the general aspect of the copulatory apparatus.

809 They can be distinguished from each other a number of small anatomical details: (a) the

810 pharyngeal pouch is $0.75 \mathrm{~mm}$ anterior to the prostatic vesicle (vs. practically at the same level as

811 the prostatic vesicle in C. imbiri); (b) dorsal insertion of the pharynx is posteriorly shifted at the

812 equivalent of $20 \%$ the length of pharynx (vs. $7 \%$ in C. imbiri); (c) paired portion of the prostatic

813 vesicle is $1 / 3$ th of total length of this organ in C. tui (vs. half in C. tui); (d) epithelium of penis

814 papilla is underlain by a layer of circular muscle fibers, followed by a layer of longitudinal ones

815 in C. tui (vs. only a layer of circular muscle in C. imbiri); and (e) the female atrium narrows

816 abruptly towards its posterior section in C. tui (vs. gradually in C. imbiri). The molecular-based

817 phylogeny shows these two species as very close genetically, nonetheless, the molecular

818 delimitation identifies them as two clearly distinct species, which reinforces the small anatomical

819 differences as being species-specific.

820

821 Cratera paraitinga Araujo, Carbayo, Riutort \& Álvarez-Presas, sp. nov.

822 urn:lsid:zoobank.org:act:7B3F43A7-2794-42F4-B99F-B8C062F972CF

823

824 Etymology. The name paraitinga refers to São José do Paraitinga, former name of Salesópolis, 825 type locality of the species. The specific epithet is invariable.

826 Type locality. Estação Biológica de Boraceia, Salesópolis, São Paulo State, Brazil.

827 Distribution. Type locality only.

828 Material examined. Holotype MZUSP PL 2157 (Field code F5769), sexually mature: Estação

829 Biológica de Boraceia, Salesópolis, São Paulo State, Brazil (-23.65413, -45.88884). coll. F.

830 Carbayo and co-workers, 20 April 2013. Transverse sections of cephalic extremity on 19 slides;

831 horizontal sections of a portion immediately behind on 71 slides; transverse sections of pre-

832 pharyngeal on 22 slides; sagittal sections of the pharynx on 33 slides; sagittal sections of 
833 copulatory apparatus on 60 slides. Paratype MZUSP PL 2156 (Field code F5745), incompletely

834 mature: Ibidem. Transverse sections of cephalic extremity on 11 slides; horizontal sections of a

835 body portion immediately behind cephalic region on 23 slides; transverse sections of pre-

836 pharyngeal region on 7 slides; sagittal sections of pharynx and copulatory apparatus on 12 slides.

837 Diagnosis

838 Species of Cratera up to $76 \mathrm{~mm}$ long in preserved condition; dorsal melon yellow median

839 stripe, bordered on either side by a jet black stripe, with externally to the latter a marginal traffic

840 white stripe; body margins jet black; eyes marginal; anterior 1/6th of the body colored with a

841 gradient of carmine red; pharynx cylindrical to bell-shaped; pharyngeal pouch $c a .2 \mathrm{~mm}$ anterior

842 to prostatic vesicle; distal dilation of ejaculatory duct relatively large; penis papilla as long as

843 male atrium; female atrium 2.4 times longer than the male atrium; common glandular

844 ovovitelline duct long.

\section{Description}

846

The longest and only mature specimen (holotype) measured $75 \mathrm{~mm}$ in length, and $7 \mathrm{~mm}$

847 in width. Paratype incompletely mature, $27 \mathrm{~mm}$ long and $4 \mathrm{~mm}$ wide. Body slightly lanceolate,

848 with maximum width at the level of the pharynx. Anterior to the pharynx, body narrows

849 gradually towards the rounded, anterior tip; posterior region narrows more abruptly. Dorsum

850 convex, ventral side flattened. Creeping sole, $92-95 \%$ of body width at pre-pharyngeal region

$851(\mathrm{n}=2)$. Mouth at a distance from anterior extremity equal to $63 \%$ of body length; gonopore, $83 \%$

852 (holotype).

853 Dorsum with an melon yellow median stripe, measuring $40 \%$ of the body width, on either

854 side bordered by a jet black stripe (14.5\%), with externally to it a white band (11\%); body

855 margin (4.5\%) jet black (Fig. 14A-B). Body margins of anterior $1 / 5$ th of the body colored with a

856 gradient of carmine red. Ventrally, body margins of anterior 1/6th orange brown, grey white

857 behind (Fig. 14C).

858 Each eye is formed by a single pigmented cup, 20-25 $\mu \mathrm{m}$ in diameter. No clear halos

859 around eyes were seen. Eyes contour the anterior extremity in a single row and extend

860 marginally until posterior tip. Sensory pits, $15-16 \mu \mathrm{m}$ deep, as a uniserial ventro-lateral row

861 through a body length at least equal to $15 \%$. Necks of two types of gland cells, producing

862 xanthophil and erythrophil granules, respectively, pierce pre-pharyngeal region dorsally and

863 ventrally. In addition, rhabditogen cells discharge their secretion through dorsal epidermis. 
864 Conspicuous glandular margin with abundant glands producing xanthophil granules (Fig. 15A). 865 Cutaneous musculature consisting of a subepidermal circular layer, followed by two 866 diagonals with decussate fibers, and then a longitudinal one, 35-40 $\mu \mathrm{m}$ thick (paratype and 867 holotype, respectively) dorsally and 40-45 $\mu \mathrm{m}$ thick ventrally (holotype and paratype, 868 respectively). Thickness of cutaneous musculature ranging between $6.6 \%-10.7 \%(\mathrm{n}=2)$ to body 869 height in the pre-pharyngeal region.

870 Three parenchymal muscle layers present throughout the body, all constituted by fibers 871 relatively densely packed: a dorsal layer of diagonal decussate fibers (10 $\mu \mathrm{m}$ thick, holotype), a 872 supraintestinal layer of transverse muscle fibers ( $40 \mu \mathrm{m})$, and a transverse subintestinal one (40 $873 \mu \mathrm{m})$. Dorso-ventral fibers abundant between intestinal branches.

874 Central nervous system as a ventral nerve plate. Clearly evident cerebral ganglia were not 875 observed.

876 Mouth located at the end of the anterior half of pharyngeal pouch (Fig. 15B). Pharynx

877 between cylindrical and bell-shaped, with dorsal insertion posterior to the ventral one at the 878 equivalent of $40 \%$ of pharyngeal length $(n=2)$. Esophagus length $20 \%$ of pharyngeal length $879(\mathrm{n}=2)$. Outer pharyngeal epithelium underlain by a one-fiber-thick layer $(4 \mu \mathrm{m})$ of longitudinal 880 muscle fibers, followed by a layer of circular fibers $(6 \mu \mathrm{m})$; inner pharyngeal epithelium 881 underlain by a layer $(50-100 \mu \mathrm{m})$ of circular fibers, followed by a layer $(20 \mu \mathrm{m})$ of longitudinal 882 fibers (holotype). Pharyngeal pouch $2.1 \mathrm{~mm}$ anterior to the prostatic vesicle in holotype, and 0.65 $883 \mathrm{~mm}$ in the incompletely mature paratype.

884 Testes dorsal, located under the supraintestinal muscle layer, partially placed between the 885 intestinal diverticula (Fig. 15A). Testes extend from shortly behind the level of the ovaries to 886 nearly $3 \mathrm{~mm}$ anterior to root of pharynx (holotype). Sperm ducts communicate with the 887 respective lateral diverticula of the prostatic vesicle. Extrabulbar prostatic vesicle elongate and 888 branched along its proximal 1/4th. Vesicle runs posteriorly and upwards until anterior region of 889 penis bulb. Prostatic vesicle lined with a columnar, ciliated epithelium, which is pierced by 890 numerous necks of cells producing fine erythrophil granules. A $15-\mu \mathrm{m}$-thick net of muscle fibers 891 surround the vesicle. Inside the penis papilla, prostatic vesicle communicates with a straight 892 ejaculatory duct, the latter traversing penis papilla. Ejaculatory duct widened to a conspicuous 893 along distal half of penis papilla (Fig. 15C, 16A-B). Ejaculatory duct surrounded by a $5-\mu \mathrm{m}-$ 894 thick layer of circular muscle fibers along most of its length, and by circular and longitudinal 
895 fibers on its widened portion.

896 Penis papilla conical and blunt, with dorsal insertion slightly posterior to the ventral one;

897 it is as long as male atrium (Fig. 15C, 16A). Male atrium as long as 1.4x its height, slightly

898 folded. Penis papilla and male atrium clothed with a cuboidal, non-ciliated epithelium, which is

899 pierced by necks of cells producing erythrophil granules. Quality of stain did not allow for

900 further details. Epithelium of penis papilla and that of male atrium underlain by a 3- $\mu \mathrm{m}-\mathrm{thick}$

901 layer of circular muscle fibers, followed by a $2-\mu \mathrm{m}$-thick layer of longitudinal fibers.

$902 \quad$ Vitellaria well developed. Elongated, ovoid ovaries measuring $300 \mu \mathrm{m}$ in diameter in

903 antero-posterior direction. They are located immediately above the ventral nerve plate, at a

904 distance from anterior tip equivalent to $25 \%$ of body length. Ovovitelline ducts arise from dorso-

905 lateral side of ovaries and run backwards above the ventral nerve plate. Laterally to the female

906 atrium, the oviducts curve dorso-medially and, subsequently, unite dorsally to the posterior third

907 of the female atrium to form the common glandular ovovitelline duct (Fig. 15C). Distal

908 ascending portion of the oviducts receives the openings of shell glands. The long common

909 glandular ovovitelline duct $(0.9 \mathrm{~mm}$, i.e., $1 / 3$ th of the length of female atrium) communicates

910 with female genital canal, the latter being a projection of the posterior portion of female atrium

911 that projects antero-dorsad (Fig. 15C, 16A-C). Female atrium long and funnel-shaped,

912 compressed laterally. Anterior portion of female atrium narrower than in its mid-region. Female

913 atrium 2.4 times the length of male atrium, and lined with non-ciliated epithelium, $40 \mu \mathrm{m}$ tall and

914 with multilayered aspect at its posteriormost 1/4th; otherwise, epithelium $20 \mu \mathrm{m}$ tall and

915 cuboidal-to-columnar. Necks of cells producing erythrophil granules pierce female epithelium,

916 which is underlain by a layer of circular muscle fibers (10 $\mu \mathrm{m}$ thick, holotype), followed by a

917 layer of longitudinal fibers (10 $\mu \mathrm{m}$ thick).

\section{Discussion}

919 Among all species of the genus, C. taxiarcha and C. tui resemble C. paraitinga in the

920 general color pattern of the dorsum, consisting of longitudinal stripes with black, white and

921 yellow color. However, the median stripe in C. taxiarcha is white (yellowish in C. paraitinga).

922 Cratera tui, very similar to $C$. paraitinga in the color pattern, differs from it in the width of the 923 yellowish mid-dorsal stripe (28\% of body width in $C$. tui vs. $40 \%$ in C. paraitinga).

924 Regarding the copulatory apparatus, only C. tui and C. imbiri resemble C. paraitinga in

925 the relatively long female atrium as compared to the male one. However, the two species differ 
926 from C. paraitinga in details: (a) the dilation of the ejaculatory duct is relatively small in C. tui 927 (vs. relatively large in C. paraitinga); (b) the penis papilla is shorter than the male atrium in $C$. 928 tui and C. imbiri (vs. as long as the male atrium in C. paraitinga).

929 The molecular analyses show these three species, C. tui, C. imbiri and C. paraitinga, to 930 constitute a monophyletic group, which reflects their morphological similarities but also may 931 cast some doubt on their status as separate species. However, the discovery methods of species 932 delimitation show the three as independent species, with the exception of the mPTP method. In 933 the case of the validation method (BPP), the significance of the separation of C. imbiri and $C$. 934 paraitinga is only highly supported by the models implying a small ancestral size, while the 935 support is slightly lower if we consider the ancestral population as having been large. Our results 936 could be interpreted also in the way that ancestral populations were not very large. Evidently, the 937 current situation may be a consequence of the destruction of their habitat or a lack of sampling, 938 since some areas have been explored very intensively and others are still pending sampling. Putting together all the evidence, molecular and morphological inferences reinforce one another

940 and, therefore, give more weight to the small morphological differences, which therefore, should 941 be interpreted as indicating separate species.

942

\section{General discussion}

944

945

946

947

948

949

950

Carbayo et al. (2013) proposed the first phylogenetic framework of the Geoplaninae. That phylogeny was inferred from one mitochondrial region (COI) and three nuclear ones (18S, 28S rDNA and EF) of 68 putative species, eight of them representing Cratera lineages (plus one immature representative). At that time, only three species of Cratera were known (C. crioula, $C$. pseudovaginuloides and C. tamoia). Later, three of the undescribed species considered in that study were formally described (C. cuarassu; C. picuia, C. arucuia) (Carbayo \& Almeida, 2015; Lago-Barcia \& Carbayo, 2018). Two species included in the Carbayo et al (2013) phylogeny that had remained morphologically unstudied, are described in the present work, namely C. assu and C. tui.

In the present study, three new species (C. imbiri, C. paraitinga, C. boja) are also included. The phylogenetic relationships between all these 11 species have been examined here through comparative analysis of six concatenated DNA regions (two mitochondrial fragments 
957 and four nuclear).

958 Without taking into consideration differences in representativeness, the topology of our 959 phylogeny matches that of Carbayo et al (2013), except for the position of C. tamoia and C.

960 crioula. In the phylogeny from 2013, C. tamoia is sister of the remaining species of an in-group 961 including C. crioula, whereas in the present phylogeny, C. crioula + C. assu is the sister clade of 962 the remaining members of the in-group, which includes C. tamoia. This is a relevant result, due 963 to a difference in taxon sampling. As more species are included in the present study, 964 relationships are resolved that could not be observed in the phylogenies of 2013, with a smaller 965 representation of species of Cratera. Lago-Barcia \& Carbayo (2018) discussed the evolution of

966

967 968

969

970

971

972

973

974

975

976

977

978

979

980

981

982

983

984

985

986

987 some morphological attributes within Cratera by analyzing them against the phylogeny of

Carbayo et al. (2013). They considered only the five species whose anatomy was known, namely C. arucuia, C. crioula, C. cuarassu, C. picuia, and C. pseudovaginuloides. They interpreted that the distal widening of the ejaculatory duct originated in the common ancestor of all Cratera members and was secondarily lost in the last common ancestor of C. tamoia, C. crioula, and C. arucuia. For this feature, as well as other characters (roof of the male atrium pierced by necks of numerous cyanophil glands; prostatic vesicle dorsally located; $90^{\circ}$ rotation of the penis papilla), they concluded that "diagnostic character states of the genus can be lost or modified within recently evolved in-groups of Cratera, hence puzzling species classification" (Lago-Barcia \& Carbayo, 2018).

In the light of our new phylogenetic framework, loss of the widening of the distal section of the ejaculatory duct apparently evolved independently in two lineages, thus giving rise to the condition is C. crioula, and that in C. picuia and C. arucuia. However, this new framework does not invalidate the above-quoted conclusion of Lago-Barcia \& Carbayo. Moreover, our data corroborates their conclusion, as demonstrated in the following five selected examples. (i) The position of the prostatic vesicle, either internal to the penis bulb or external to it, appears to have independently evolved from an external to an internal position only in C. tamoia and C. picuia. An equally parsimonious interpretation would be that the internal position of the prostatic vesicle would have evolved in the common ancestor of C. tamoia $+C$. arucuia + C. picuia and that this condition would have reversed in C. arucuia. (ii) In similar vein, a penis papilla longer than the male atrium may have evolved in the common ancestor of $C$. boja, $C$. pseudovaginuloides, $C$. crioula, C. assu, C. picuia, C. arucuia and C. tamoia, while this condition would independently 
988 and secondarily have been lost in C. boja and C. tamoia. (iii) In C. picuia and C. boja, the dorsal 989 surface of the male atrium is traversed by a mass of necks of cells producing cyanophil granules. 990 This situation is best explained as two evolutionary independent acquisitions. (iv) The most 991 parsimonious explanation for the very reduced or even absence of the common glandular 992 ovovitelline duct in C. picuia, C. assu and C. boja is independent loss in each of these species, 993 none of which shares a sister-group relationship.

994 Against this trend, the relatively long female atrium, in comparison with the male atrium, 995 appears to be homologous in all members of Cratera. The female atrium is usually as long as the 996 male one. However, in C. tui, C. imbiri, and C. paraitinga, the female atrium is $>2.4$ times 997 longer than the male one. These three species constitute a monophyletic group and most 998 probably this character state evolved in the common ancestor of these species. These three 999 species are similar to each other, not only in this trait, but also in the traditional characteristics 1000 used in the classification of Geoplaninae. For this reason, our molecular approach in the species 1001 delimitation proved to be essential in their discovery as independent lineages.

1002 The causes underlying the evolutionary differences between the copulatory organs in land 1003 triclads remain unclear. Absence of relevant apomorphies in other related groups, such as the 1004 freshwater planarian genus Girardia (Dugesiidae), also complicated assignment of species to the 1005 genus (Sluys, Hauser \& Wirth, 1997). In the case of land planarians, morphological differences may be related to the fact that each species belongs to a lineage that has evolved independently 1007 for a long period, as exemplified by the land planarian Cephaloflexa bergi (Graff, 1899) 1008 (Geoplaninae), a species that originated about 7 Mya (Álvarez-Presas et al., 2014).

1009 The inescapable conclusion from this argumentation is that Cratera land planarians 1010 apparently devolved fast-evoving features, even those that diagnose the genus, such as the 1011 dilation of the ejaculatory duct. Such rapidly evolving structures can mislead a natural 1012 classification of Cratera and its relatives when systematics is solely based on morphology. 1013 An interesting aspect of land planarians is their restricted geographical distribution. Most 1014 species are known from only one or a few localities (Carbayo \& E. M. Froehlich, 2008). In the 1015 present study only Cratera tui was found in an additional locality apart from the type locality. 1016 But even these two localities are only $30 \mathrm{~km}$ apart from each other. Although sampling artifacts 1017 may underlie such presumably restricted distributions (Sluys, 1999), it is also possible that they 1018 reflect actual species distributions. Our data support the latter hypothesys in the case of Cratera 
1019 because we performed an intensive sampling effort in the four studied areas that resulted in the 1020 distributional ranges reported in this study.

$1021 \quad$ We hypothesize that closely related Cratera species with such fast-evolving features, and 1022 very restricted areas of distribution may be the result of relatively recent speciation events linked 1023 to the postglacial history of the area. However, thorough studies, including NGS data and robust 1024 population analyses, will be necessary to test this hypothesis.

1025

1026

\section{Conclusions}

1028

1029

Molecular-based phylogenies and species delimitation methods provide hypotheses on 1030 species recognition that are independent from the morphology-based approach. Congruence of both approaches allowed us to recognize evolutionarily independent lineages, i.e, species, and to 1032 independently evaluate small morphological differences between the individuals as a signal of separate species status. Otherwise, most likely we had ranked C. tui, C. imbiri and C. paraitinga under one nominal species.

Furthermore, the new molecular markers for species delimitation and phylogenetic inference developed for the first time in the present work resulted in highly resolved phylogenbetic trees of terrestrial planarians. We have expanded the number of informative molecular markers by adding two new molecules (Tnuc813 and Nd4toCox1) as a result of the use of new generation molecular tools. This result should not be overlooked, since the availability of molecular markers has always been a limiting factor in the molecular systematics 1041 of these animals.

\section{Acknowledgements}

We thank Celso Barbieri Junior, Cláudia Olivares, Débora Redivo, Erica Panachuk de 1047 Souza, Júlio Pedroni, Leonardo Zerbone, Marcos Santos Silva, Marília Jucá and Welton Araújo 1048 (EACH, USP) for assistance during the sampling. Thanks are due to Geison Castro da Silveira, 
1049 Lucas Beltrami, and Ítalo Silva de Oliveira Souza (EACH, USP) for histological processing.

1050 Gema Blasco is thanked for the wet lab support. This paper was improved after careful revision 1051 by Ronald Sluys, Lisandro Negrete and Victor Hugo Valiati.

1052

1053

1054

\section{References}

1055

1056

Almeida AL, Marques FPL, Carbayo F. 2019. 'Endless forms most beautiful': taxonomic

1057 revision of the planarian Geoplana vaginuloides (Darwin, 1844) and discovery of numerous

1058 congeners (Platyhelminthes: Tricladida). Zoological Journal of the Linnean Society 185: 1-65.

1059 https://doi.org/10.1093/zoolinnean/zly022

1060

Álvarez-Presas M, Carbayo F, Rozas J, Riutort M. 2011. Land planarians (Platyhelminthes)

1061 as a model organism for fine-scale phylogeographic studies: understanding patterns of

1062 biodiversity in the Brazilian Atlantic Forest hotspot. Journal of Evolutionary Biology 24: 887896. https://doi.org/10.1111/j.1420-9101.2010.02220.x

1064 Álvarez-Presas, M., Sánchez-Gracia, A., Carbayo, F., Rozas, J., \& Riutort, M. 2014.

1065 Insights into the origin and distribution of biodiversity in the Brazilian Atlantic forest hot spot: a statistical phylogeographic study using a low-dispersal organism. Heredity 112: 656-665.

1067 https://doi.org/10.1038/hdy.2014.3

1068 Ayres DL, Darling A, Zwickl DJ, Beerli P, Holder MT, Lewis PO, Huelsenbeck JP, Ronquist F, Swofford DL, Cummings MP, Rambaut A, Suchard MA. 2012. BEAGLE: An application programming interface and high-performance computing library for statistical

1071 phylogenetics. Systematic Biology 61: 170-173. https://doi.org/10.1093/sysbio/syr100

1072 Boll, PK, Amaral SV, Leal-Zanchet AM. 2019. Two new land planarian species

1073 (Platyhelminthes: Tricladida: Geoplanidae) from protected areas in southern Brazil. Zootaxa 10744664 (4): 535-550. https://doi.org/10.11646/zootaxa.4664.4.5

1075 Bouckaert R, Heled J, Kühnert D, Vaughan T, Wu C-H, Xie D, Suchard MA, Rambaut A, 1076 Drummond AJ. 2014. BEAST2: A software platform for Bayesian evolutionary analysis. PLOS 1077 Computational Biology. https://doi.org/10.1371/journal.pcbi.1003537 
1078 Carbayo F, Froehlich EM. 2008. Estado do conhecimento dos macroturbelários

1079 (Platyhelminthes) do Brasil. Biota Neotropica 8:177-197.

1080 http://www.biotaneotropica.org.br/v8n4/ pt/abstract?thematic-review+bn01908042008

1081 Carbayo F, Álvarez-Presas M, Olivares CT, Marques FPL, Froehlich EM, Riutort M.

1082 2013. Molecular phylogeny of Geoplaninae (Platyhelminthes) challenges current classification:

1083 proposal of taxonomic actions. Zoologica Scripta 42: 508-528.

1084 https://doi.org/10.1111/zsc.12019

1085 Carbayo F, \& Almeida AL. 2015. Anatomical deviation of male organs of land planarians from

1086 Rio de Janeiro, Brazil, with description of two new species of Cratera (Platyhelminthes,

1087 Tricladida). Zootaxa 3931(1): 027-040. https://doi.org/10.11646/zootaxa.3931.1.2

1088 Carbayo F, Silva MS, Riutort M, Álvarez-Presas M. 2018. Rolling into the deep of the land

1089 planarian genus Choeradoplana (Tricladida, Continenticola, Geoplanidae) taxonomy. Organisms

1090 Diversity \& Evolution 18: 187-210. https://doi.org/10.1007/s13127-017-0352-4

1091 Cason JE. 1950. A rapid one-step Mallory-Heidenhain stain for connective tissue. Stain

1092 Technology 25(4): 225-226. https://doi.org/10.3109/10520295009110996

1093 Darriba D, Taboada GL, Doallo R, Posada D. 2012. jModelTest 2: more models, new

1094 heuristics and parallel computing. Nature Methods 9: 772. https://doi.org/10.1038/nmeth.2109

1095 de Queiroz, K. 1998. The general lineage concept of species, species criteria, and the process of 1096 speciation and terminological recommendations. In D. J. Howard \& S. H. Berlocher (Eds.),

1097 Endless forms: Species and speciation (57-75). Oxford, UK: Oxford University Press.

1098 Froehlich EM. 1955. Sobre espécies brasileiras do gênero Geoplana. Boletim da Faculdade de

1099 Filosofia, Ciências e Letras da Universidade de São Paulo, Série Zoologia 19: 289-369.

1100 Hall TA. 1999. BioEdit: a user-friendly biological sequence alignment editor and analysis

1101 program for Windows 95/98/NT. Nucleic acids symposium series 41: 95-98.

1102 Kapli P, Lutteropp S, Zhang J, Kobert K, Pavlidis P, Stamatakis A, Flouri T. 2017. Multi-

1103 rate Poisson tree processes for single-locus species delimitation under maximum likelihood and

1104 Markov chain Monte Carlo. Bioinformatics 33: 1630-1638.

1105 https://doi.org/10.1093/bioinformatics/btx025

1106 Katoh K, Rozewicki J, Yamada KD. 2017. MAFFT online service: multiple sequence

1107 alignment, interactive sequence choice and visualization. Briefings in Bioinformatics bbx108: 1-

1108 7. https://doi.org/10.1093/bib/bbx108

Peer] reviewing PDF | (2020:04:48478:1:1:NEW 8 Jul 2020) 
1109 Lago-Barcia D \& Carbayo F. 2018. Taxonomic revision of four species of the Neotropical land 1110 planarian genera Cratera and Geoplana (Platyhelminthes, Tricladida) with a description of two 1111 new species and an emendation of Cratera. Zootaxa 4500 (4): 517-542.

1112 https://doi.org/10.11646/zootaxa.4500.4.3

1113 Lanfear R, Frandsen PB, Wright AM, Senfeld T, Calcott B. 2017. Partitionfinder 2: New

1114 methods for selecting partitioned models of evolution for molecular and morphological

1115 phylogenetic analyses. Molecular Biology and Evolution 34: 772-773.

1116 https://doi.org/10.1093/molbev/msw260

1117 Leria L, Vila-Farré M, Álvarez-Presas M, Sánchez-Gracia A, Rozas J, Sluys R, Riutort M.

1118 2020. Cryptic species delineation in freshwater planarians of the genus Dugesia

1119 (Platyhelminthes, Tricladida): Extreme intraindividual genetic diversity, morphological stasis,

1120 and karyological variability. Molecular Phylogenetics and Evolution, 143: 106496.

1121 https://doi.org/10.1016/j.ympev.2019.05.010

1122 Marcus E. 1951. Turbellaria brasileiros (9). Boletim da Faculdade de Filosofia, Ciências e

1123 Letras da Universidade de São Paulo, Série Zoologia 16: 1-217.

1124 Miller MA, Pfeiffer W, Schwartz T. 2010. Creating the CIPRES Science Gateway for 1125 Inference of Large Phylogenetic Trees. Proceedings of the Gateway Computing Environments 1126 Workshop (GCE). New Orleans, LA; 1-8. https://doi.org/10.1109/GCE.2010.5676129

1127 Minh BQ, Nguyen MAT, Von Haeseler A. 2013. Ultrafast approximation for phylogenetic 1128 bootstrap. Molecular Biology and Evolution 30: 1188-1195.

1129 https://doi.org/10.1093/molbev/mst024

1130 Negrete L, \& Brusa F. 2016. First report of the genus Cratera (Platyhelminthes, Geoplanidae)

1131 in Argentina, with description of a new species and comments on the species of the genus.

1132 ZooKeys 610: 1-12. https://doi.org/10.3897/zookeys.610.9465

1133 Nguyen LT, Schmidt HA, Von Haeseler A, Minh BQ. 2015. IQ-TREE: A fast and effective

1134 stochastic algorithm for estimating maximum-likelihood phylogenies. Molecular Biology and

1135 Evolution 32: 268-274. https://doi.org/10.1093/molbev/msu300

1136 Puillandre N, Modica MV, Zhang Y, Sirovich L, Boisselier MC, Cruaud C, Holford M,

1137 Samadi S. 2012a. Large-scale species delimitation method for hyperdiverse groups. Molecular

1138 Ecology 21: 2671-2691. https://doi.org/10.1111/j.1365-294X.2012.05559.x 
1139 Puillandre N, Lambert A, Brouillet S, Achaz G. 2012b. ABGD, Automatic Barcode Gap

1140 Discovery for primary species delimitation. Molecular Ecology 21: 1864-1877.

1141 https://doi.org/10.1111/j.1365-294X.2011.05239.X

1142 Ronquist F, Teslenko M, Van Der Mark P, Ayres DL, Darling A, Höhna S, Larget B, Liu

1143 L, Suchard MA, Huelsenbeck JP. 2012. MrBayes 3.2: Efficient Bayesian Phylogenetic

1144 Inference and Model Choice Across a Large Model Space. Systematic Biology 61: 539-542.

1145 https://doi.org/10.1093/sysbio/sys029

1146 Riester A. 1938. Beiträge zur Geoplaniden-Fauna Brasiliens. Abhandlungen der

1147 Senckenbergischen Naturforschenden Gesellschaft 441: 1-88.

1148 Rossi, I, Fontoura, M, Amaral S, Leal-Zanchet AM. 2014. A new species of land flatworm

1149 (Platyhelminthes: Continenticola) from areas of Araucaria Forest in southern Brazil. Zootaxa

11503794 (4): 514-524. http://dx.doi.org/10.11646/zootaxa.3794.4.2

1151 Rossi I, Amaral SV, Ribeiro GG, Cauduro GP, Fick I, Valiati VH, Leal-Zanchet AM. 2016.

1152 Two new Geoplaninae species (Platyhelminthes: Continenticola) from Southern Brazil based on

1153 an integrative taxonomic approach. Journal of Natural History 50 (13-14): 787-815.

1154 https://doi.org/10.1080/00222933.2015.1084057

1155 Rossi I \& Leal-Zanchet A. 2017. Three new species of Cratera Carbayo et al., 2013 from

1156 Araucaria forests with a key to species of the genus (Platyhelminthes, Continenticola). ZooKeys

1157 643: 1-32. https://doi.org/10.3897/zookeys.643.11093

1158 Sáez, A. G., \& Lozano, E. 2005. Body doubles. Nature, 433(7022): 111.

1159 https://doi.org/10.1038/433111a

1160 Sluys R, Hauser J, Wirth QJ. 1997. Deviation from the Groundplan: a unique new species of

1161 freshwater planarian from South Brazil (Platyhelminthes, Tridadida, Paludicola). Journal of

1162 Zoology 241(3): 593-601. https://doi.org/10.1111/j.1469-7998.1997.tb04851.x

1163 Sluys R. 1999. Global diversity of land planarians (Platyhelminthes, Tricladida, Terricola): a

1164 new indicator-taxon in biodiversity and conservation studies. Biodiversity \& Conservation 8(12):

1165 1663-1681. https://doi.org/10.1023/A:1008994925673

1166 Sluys R, Mateos E, Riutort M, Alvarez-Presas M. 2016. Towards a comprehensive,

1167 integrative analysis of the diversity of European microplaninid land flatworms (Platyhelminthes,

1168 Tricladida, Microplaninae), with the description of two peculiar new species. Systematics and

1169 Biodiversity 14(1): 9-31. https://doi.org/10.1080/14772000.2015.1103323

Peer] reviewing PDF | (2020:04:48478:1:1:NEW 8 Jul 2020) 
1170 Sluys R. 2016. Invasion of the flatworms. American Scientist 104(5): 288-295.

1171 https://doi.org/10.1511/2016.122.288

1172 Talavera G \& Castresana J. 2007. Improvement of Phylogenies after Removing Divergent and

1173 Ambiguously Aligned Blocks from Protein Sequence Alignments. Systematic Biology 56: 564-

1174 577. https://doi.org/10.1080/10635150701472164

1175 Tibiriçá LC. 1984. Dicionário Tupi-Português. Traço ed., São Paulo, 200 pp.

1176 Yang $\mathbf{Z}$ \& Rannala B. 2010. Bayesian species delimitation using multilocus sequence data.

1177 Proceedings of the National Academy of Sciences 107: 9264-9269.

1178 https://doi.org/10.1073/pnas.0913022107

1179 Yang Z \& Rannala B. 2014. Unguided species delimitation using DNA sequence data from

1180 multiple loci. Molecular Biology and Evolution 31: 3125-3135.

1181 https://doi.org/10.1093/molbev/msu279

1182 Yang Z. 2015. The BPP program for species tree estimation and species delimitation. Current

1183 Zoology 61: 854-865. https://doi.org/10.1093/czoolo/61.5.854 
Figure 1

Map showing the sampling sites generated with DIVA-GIS.

Records of the five species of Cratera described in this paper. Map generated with DIVA-GIS 7.5 (http://swww.diva-gis.org/Data)

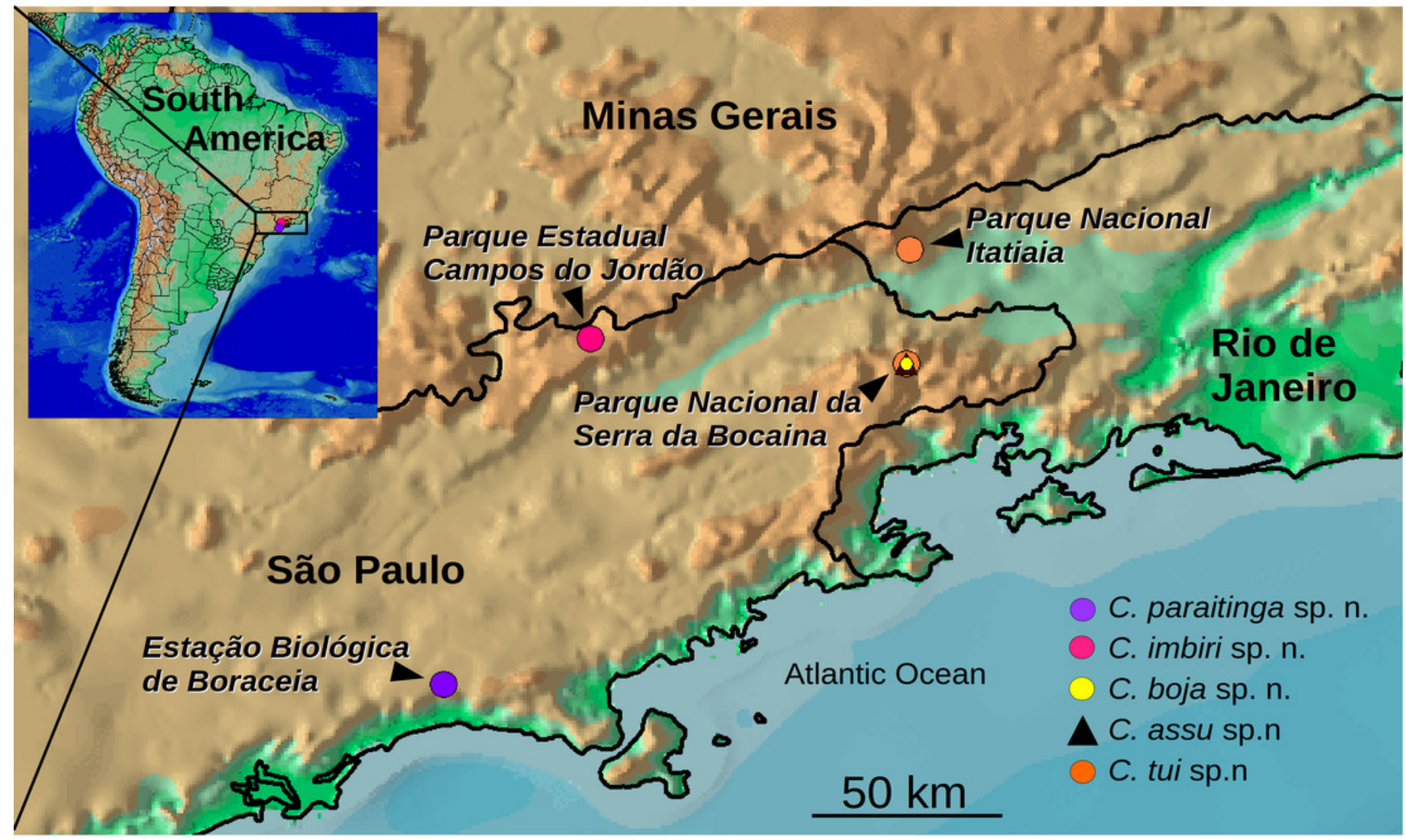




\section{Figure 2}

Phylogenetic tree showing the molecular results.

Phylogenetic tree showing the topology obtained by Bayesian Inference with the information of the concatenated six genes (18S rDNA + COI + 28S rDNA + Tnuc813 + EF + Nd4toCox1). Numbers at the nodes correspond to bootstrap values of the maximum likelihood analysis (left) and those of Bayesian posterior probability (to the right). Correspondence with the Primary Species Hypothesis assigned by the molecular species delimitation methods is indicated at the nodes. Vertical bars to the right of the phylogeny show the summary of the species delimitation analyses by ABGD (purple), mPTP (yellow), BPP (green), and morphological (orange) approaches. Scale bar represents substitutions per site.

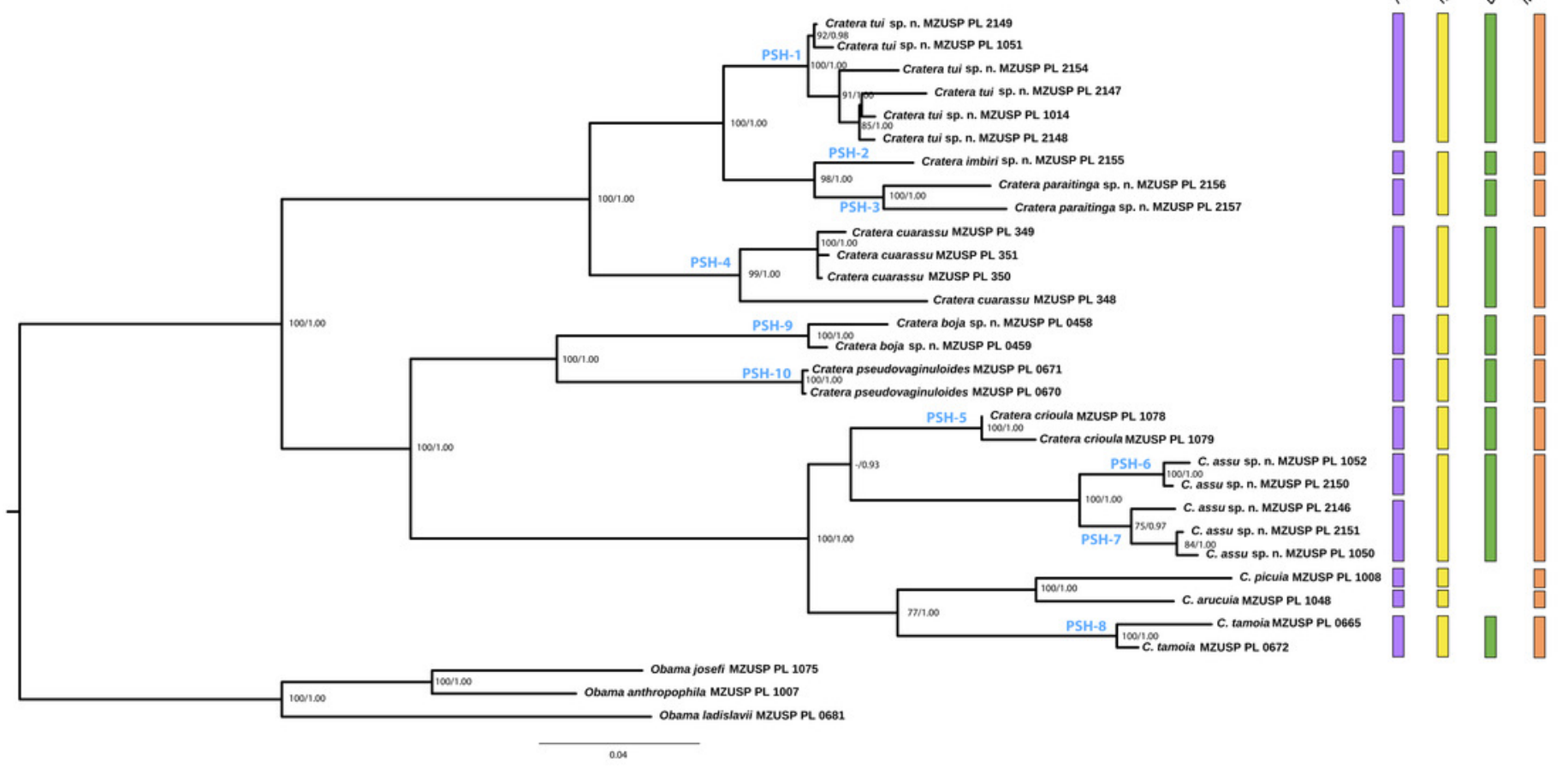


Figure 3

Results of BPP molecular species delimitation.

Results of BPP represented in the species tree estimated with *BEAST for the genus Cratera.

Colored squares of the nodes represent PP values for each of the applied models (M1, left up, M2, right up, M3, left down, M4, right down). Colors correspond to PP values: 1 (blue), > 0.95 (orange), or $<0.95$ (green). Nomenclature of Primary Species Hypothesis (PSH) is shown at the terminals of the branches. On the right, green letters indicate the Secondary Species Hypothesis validated by BPP. Images of the worms correspond to the new species. Scale bar represents substitutions per site.

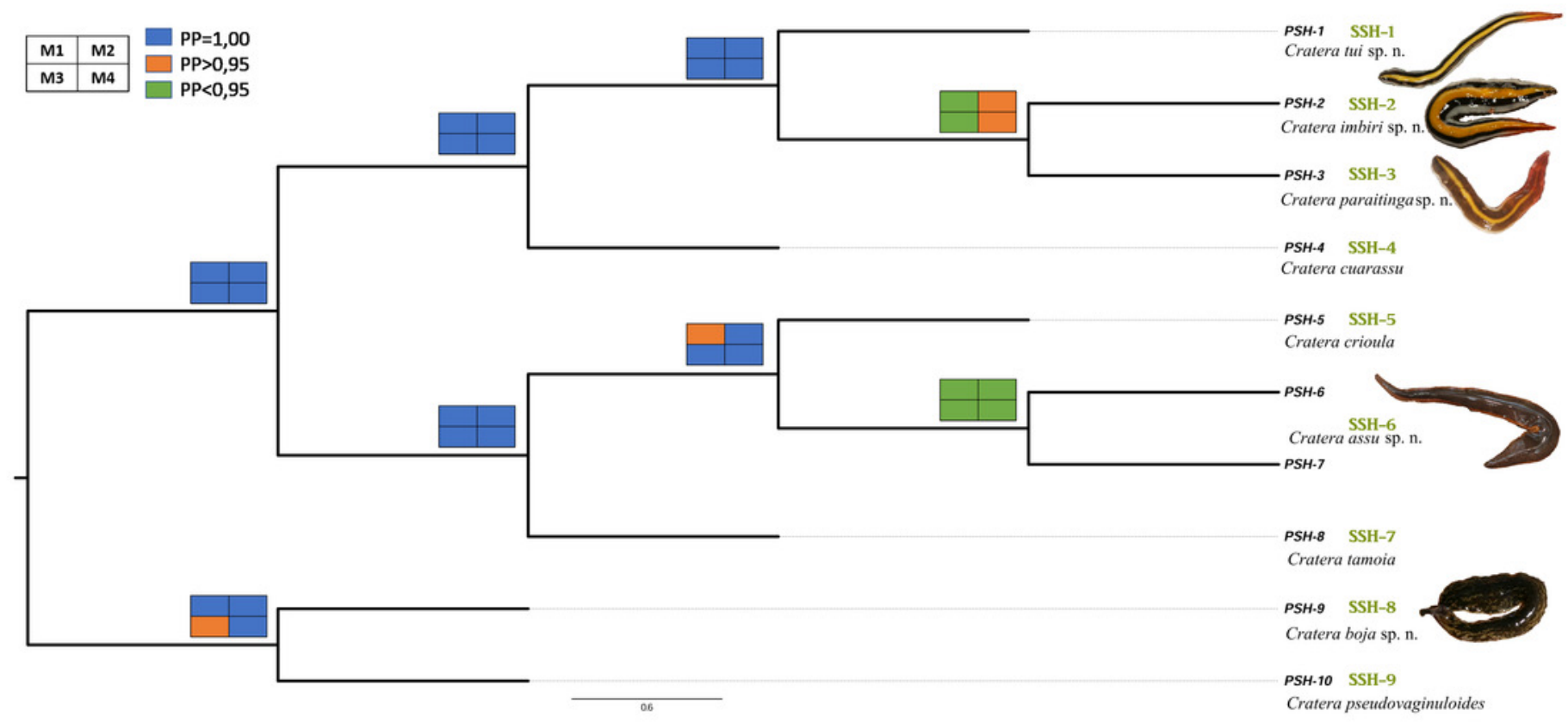




\section{Figure 4}

Cratera assu sp. n. morphological characters.

Cratera assu sp. n. (A): dorsal and ventral (inset) views of living paratype MZUSP PL 1050.

Scale bar not available. (B): dorsal and ventral (inset) views of living paratype MZUSP PL 1052. Scale bar not available. (C): photomicrograph of a sagittal section of the pharynx of holotype. (D): photomicrograph of a transverse section of pre-pharyngeal region of paratype MZUSP PL 1050.
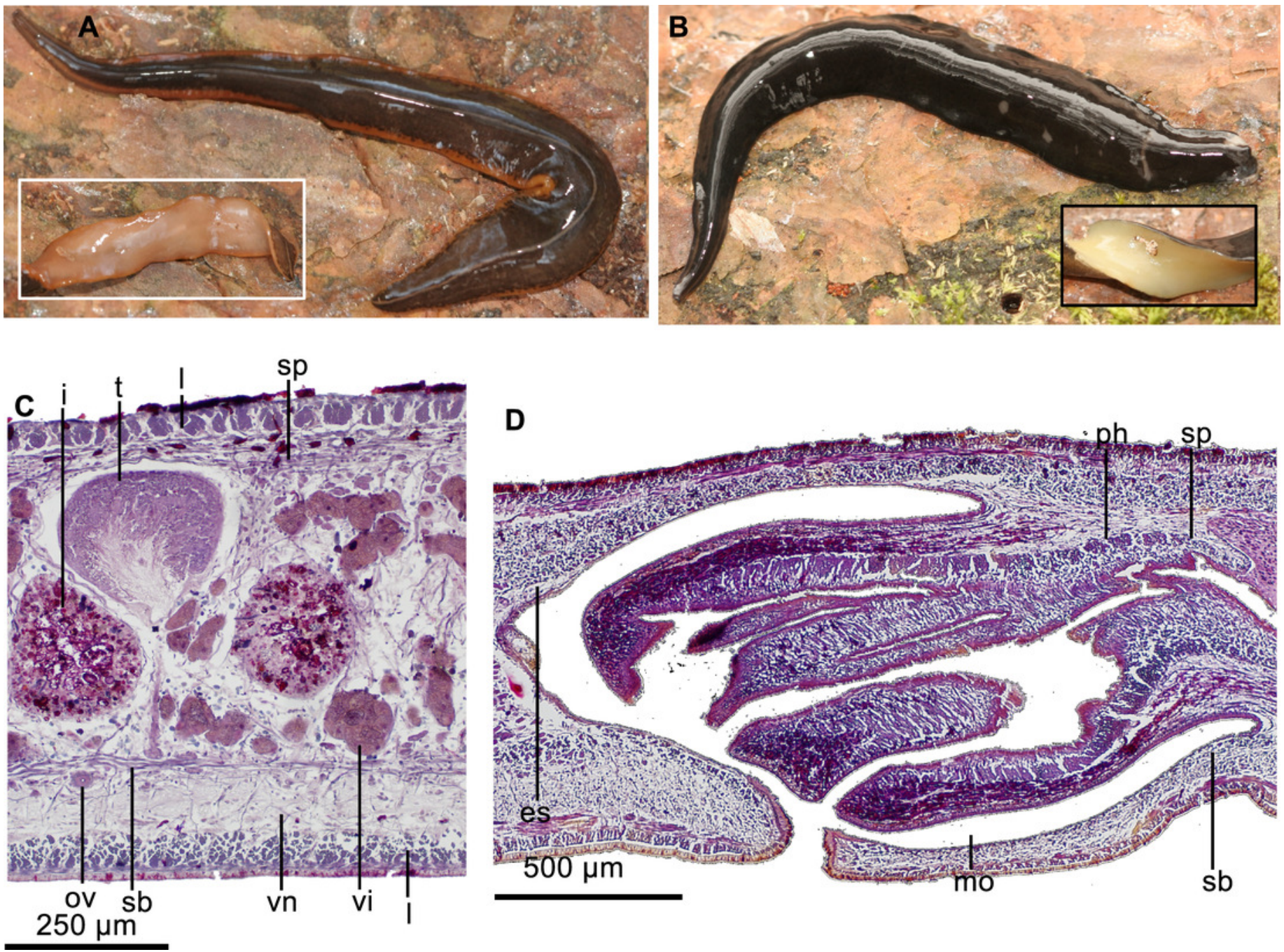


\section{Figure 5}

Cratera assu sp. n. morphological details.

Cratera assu sp. n. (A): diagrammatic representation of the copulatory apparatus of holotype from sagittal sections. (B) photomicrograph of a sagittal section of the copulatory apparatus of holotype. (C): photomicrograph of a sagittal section of the copulatory apparatus of paratype MZUSP PL 1052. (D): photomicrograph of a sagittal section of the female atrium of paratype MZUSP PL 2146. 

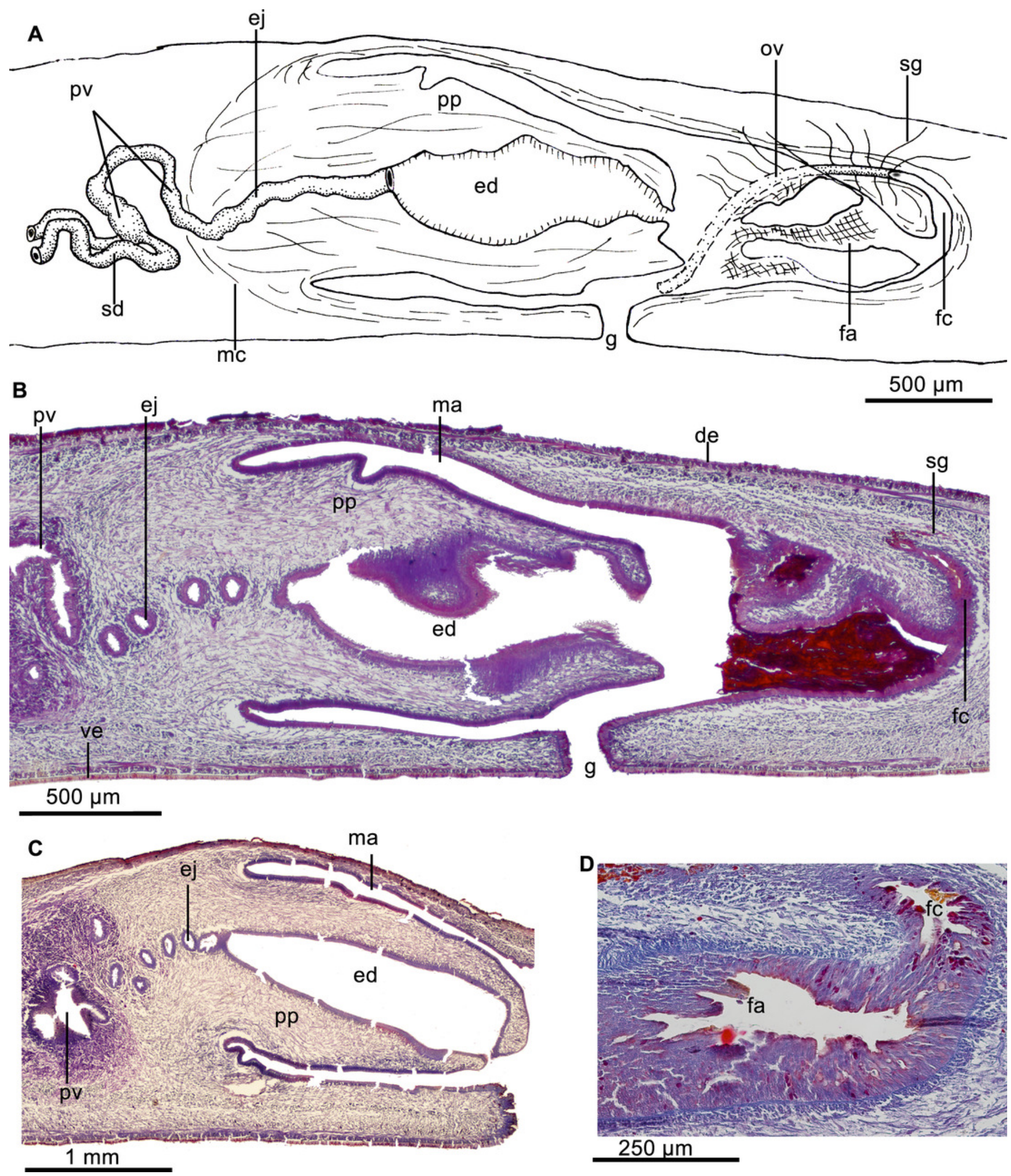


\section{Figure 6}

Cratera boja sp. n. morphological details.

Cratera boja sp. n. (A): Living holotype. Scale bar not available. (B): Dorsal view of living paratype. Scale bar not available. (C): dorsal view of holotype preserved on millimeter graph paper after cutting off a piece of the body. (D): dorsal view of the paratype, preserved on millimeter graph paper after cutting off anterior extremity of the body.
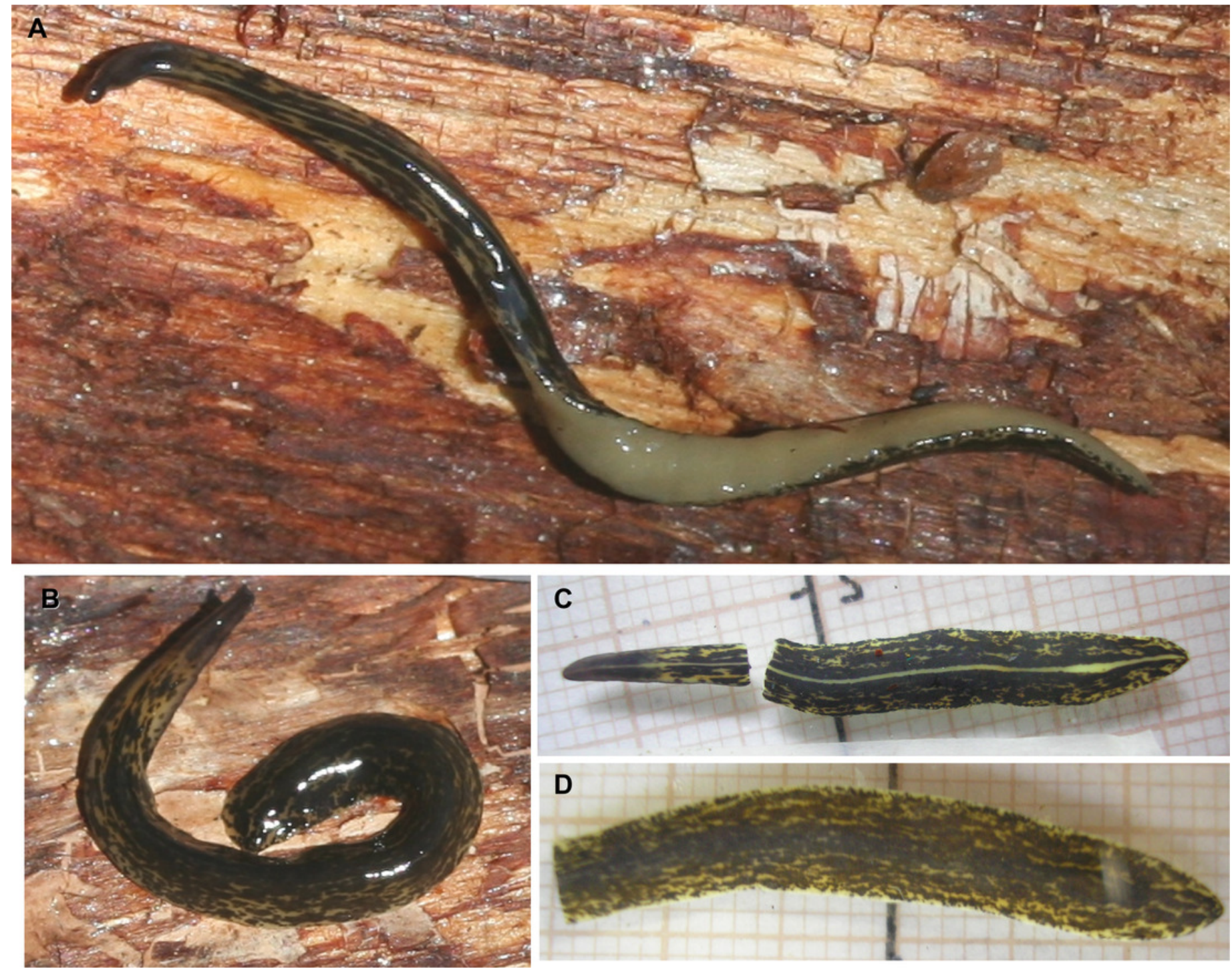


\section{Figure 7}

Cratera boja sp. n. morphological details.

Cratera boja sp. n. (A): photomicrograph of a transverse section of pre-pharyngeal region of holotype. (B): photomicrograph of a sagittal section of the pharynx of paratype. (C): diagrammatic representation of the copulatory apparatus of paratype from sagittal sections. (D): diagrammatic representation of the copulatory apparatus of holotype from sagittal sections. 


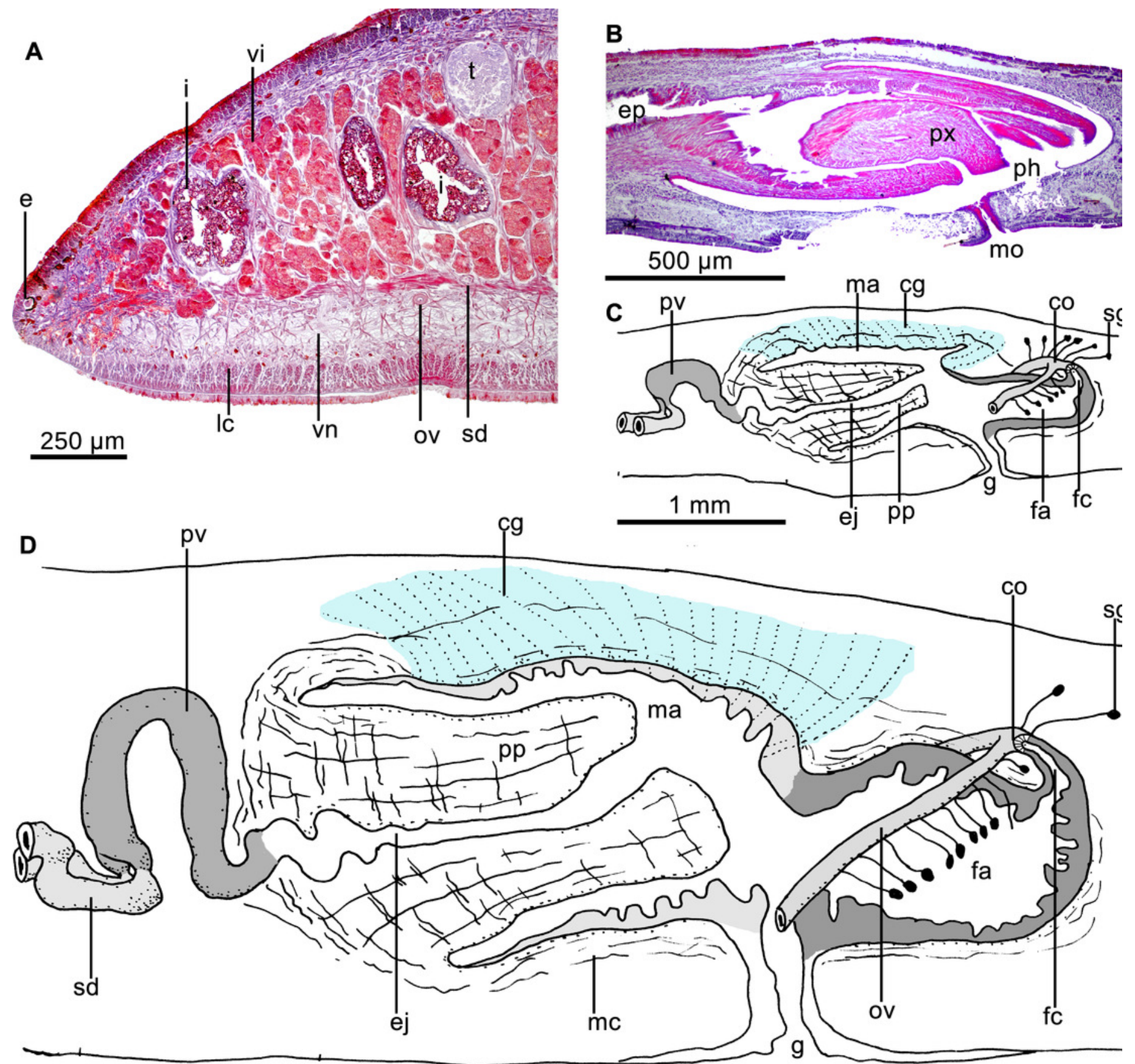

$500 \mu \mathrm{m}$ 
Figure 8

Cratera boja sp. n. morphological features.

Cratera boja sp. n. Photomicrographs of sagittal sections. (A): Copulatory apparatus of paratype. (B): Female atrium of holotype. (C): Female atrium of paratype.

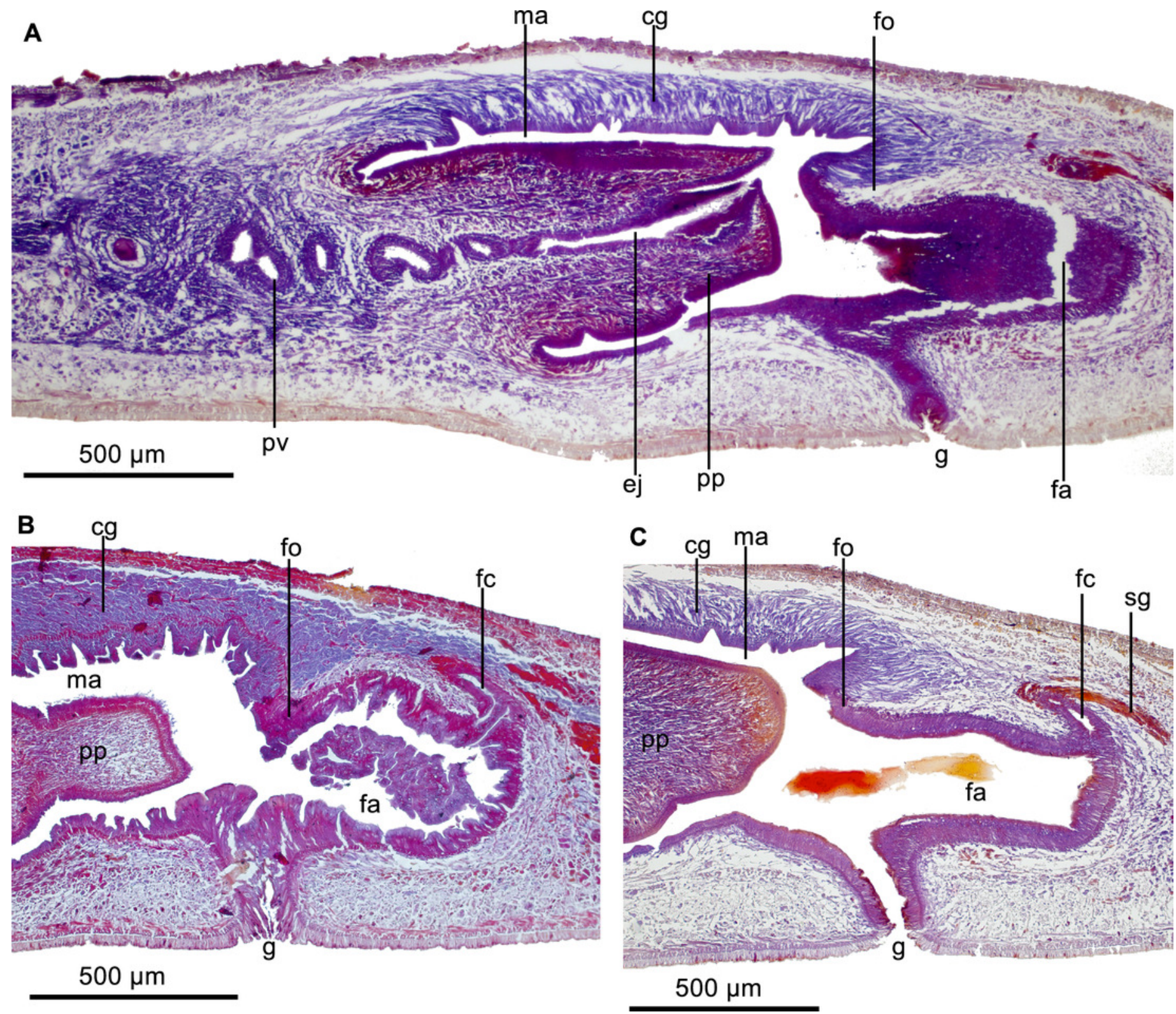




\section{Figure 9}

Cratera tui sp. n. morphological features.

Cratera tui sp. n. (A): Dorsal view of living paratype MZUSP PL 2154. (B): Dorsal view of living holotype partially twisted. Scale bars not available.

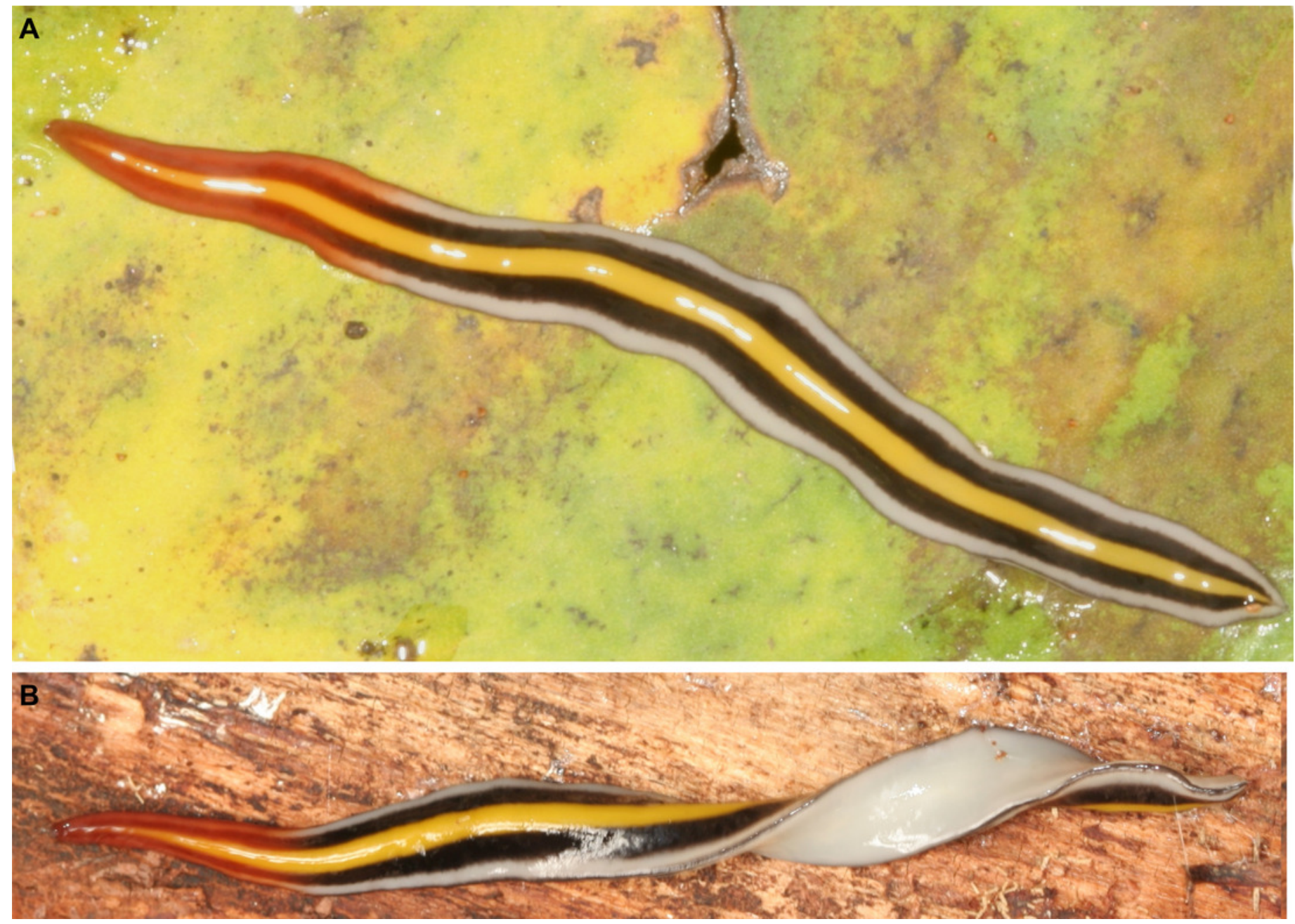




\section{Figure 10}

Cratera tui sp. n. morphological features.

Cratera tui sp. n. (A): photomicrograph of a transverse section of pre-pharyngeal region of holotype. (B): diagrammatic representation of the pharynx of paratype MZUSP PL 2154 from sagittal sections.
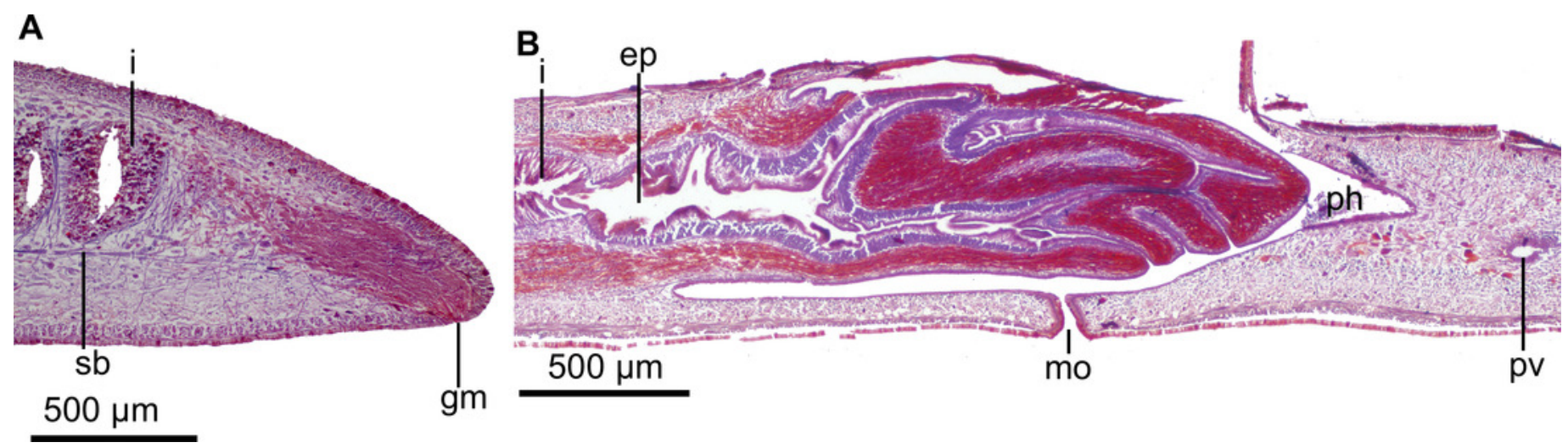
Figure 11

Cratera tui sp. n. morphological details.

Cratera tui sp. n. Holotype. (A) diagrammatic representation of the copulatory apparatus

from sagittal sections. (B): photomicrograph of a sagittal section of copulatory apparatus. (C): photomicrograph of a sagittal section penis papilla. 

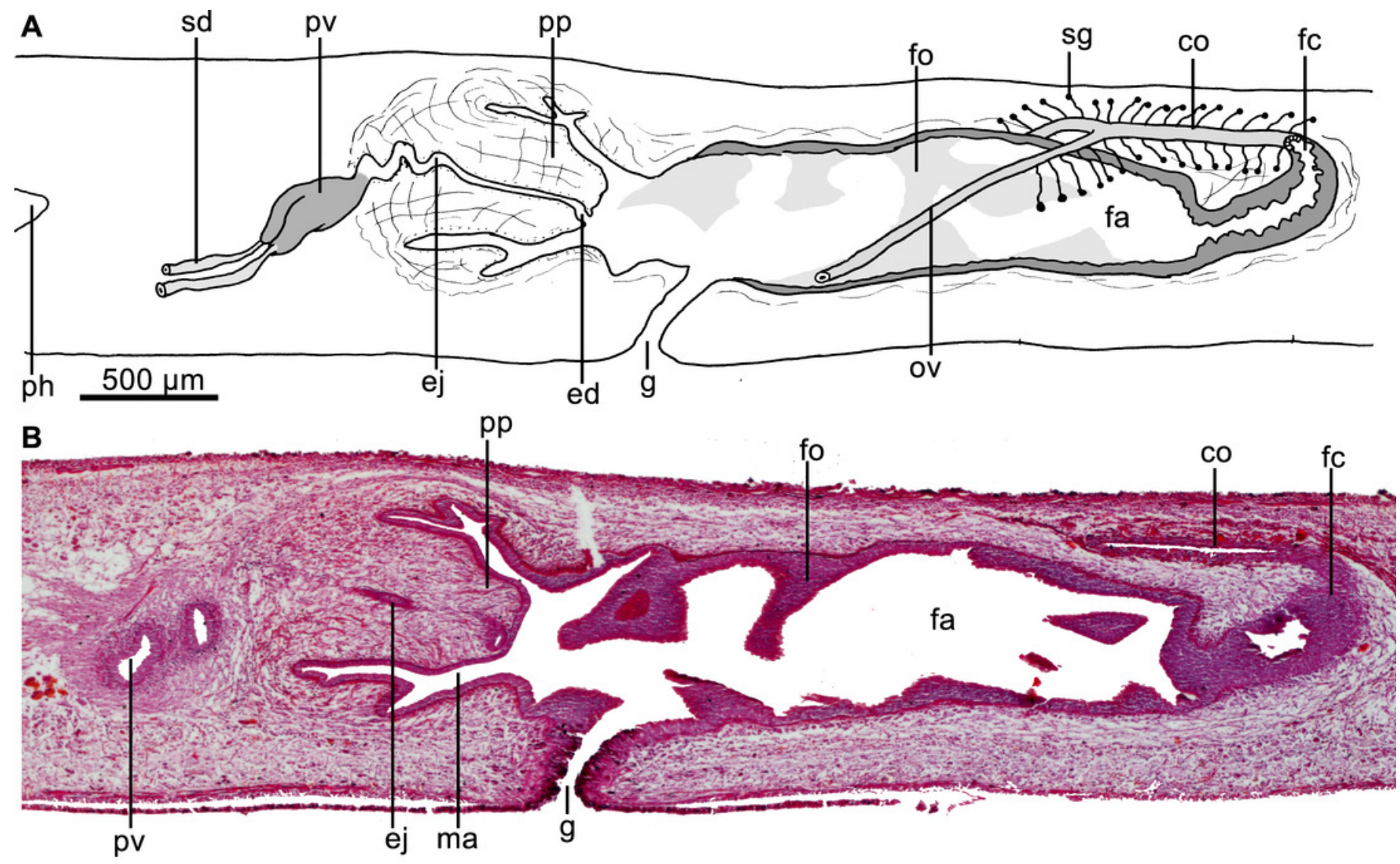

$500 \mu \mathrm{m}$

C

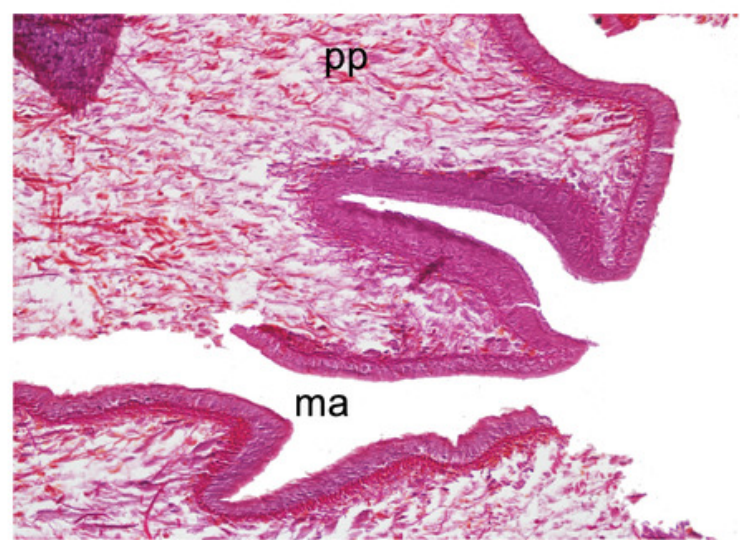

$250 \mu \mathrm{m}$ 


\section{Figure 12}

Cratera imbiri sp. n. morphological features.

Cratera imbiri sp. n. Holotype (A): Dorsal view of living specimen. Scale bar not available. (B):

Ventral view of living specimen. Scale bar not available. (C): photomicrograph of a sagittal section of pharynx.
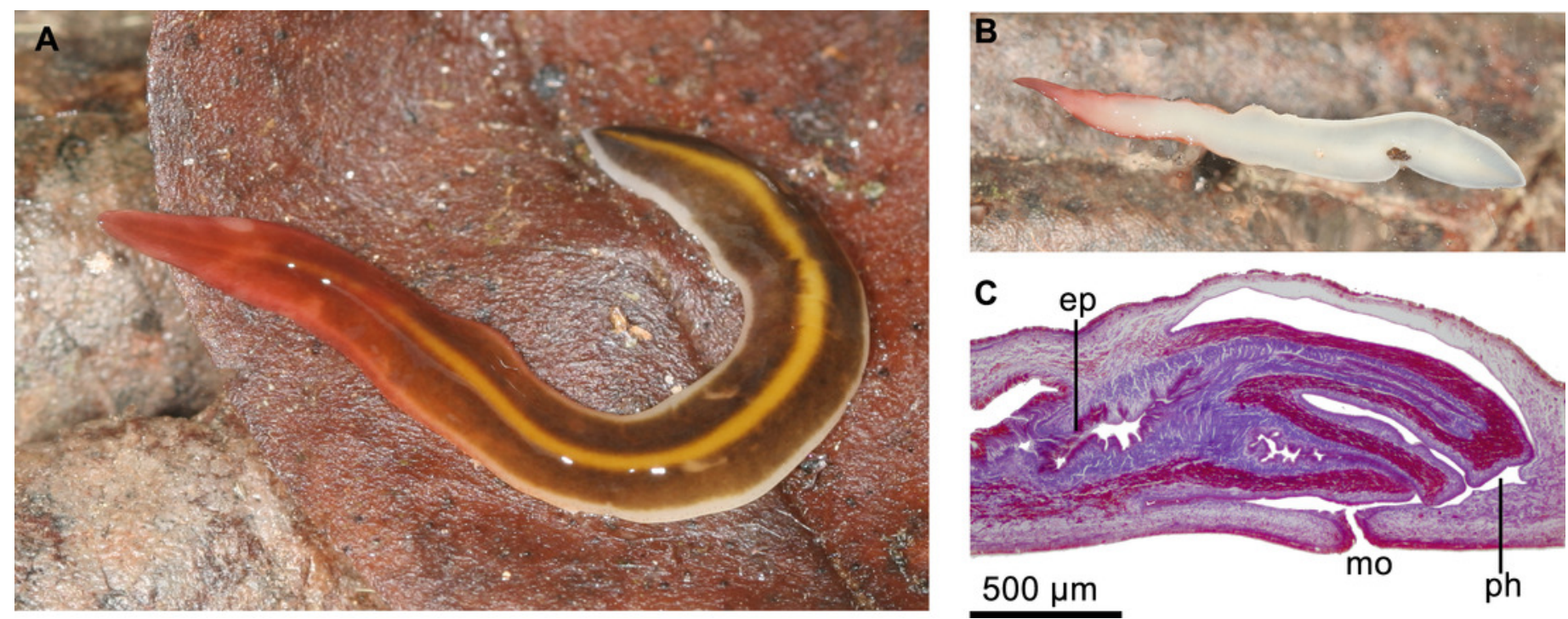


\section{Figure 13}

Cratera imbiri sp. n. morphological features.

Cratera imbiri sp. n. Holotype. (A) diagrammatic representation of the copulatory apparatus from sagittal sections. (B): photomicrograph of a sagittal section of copulatory apparatus. (C): photomicrograph of a sagittal section of male atrium. (D): photomicrograph of a horizontal section of ovary. 

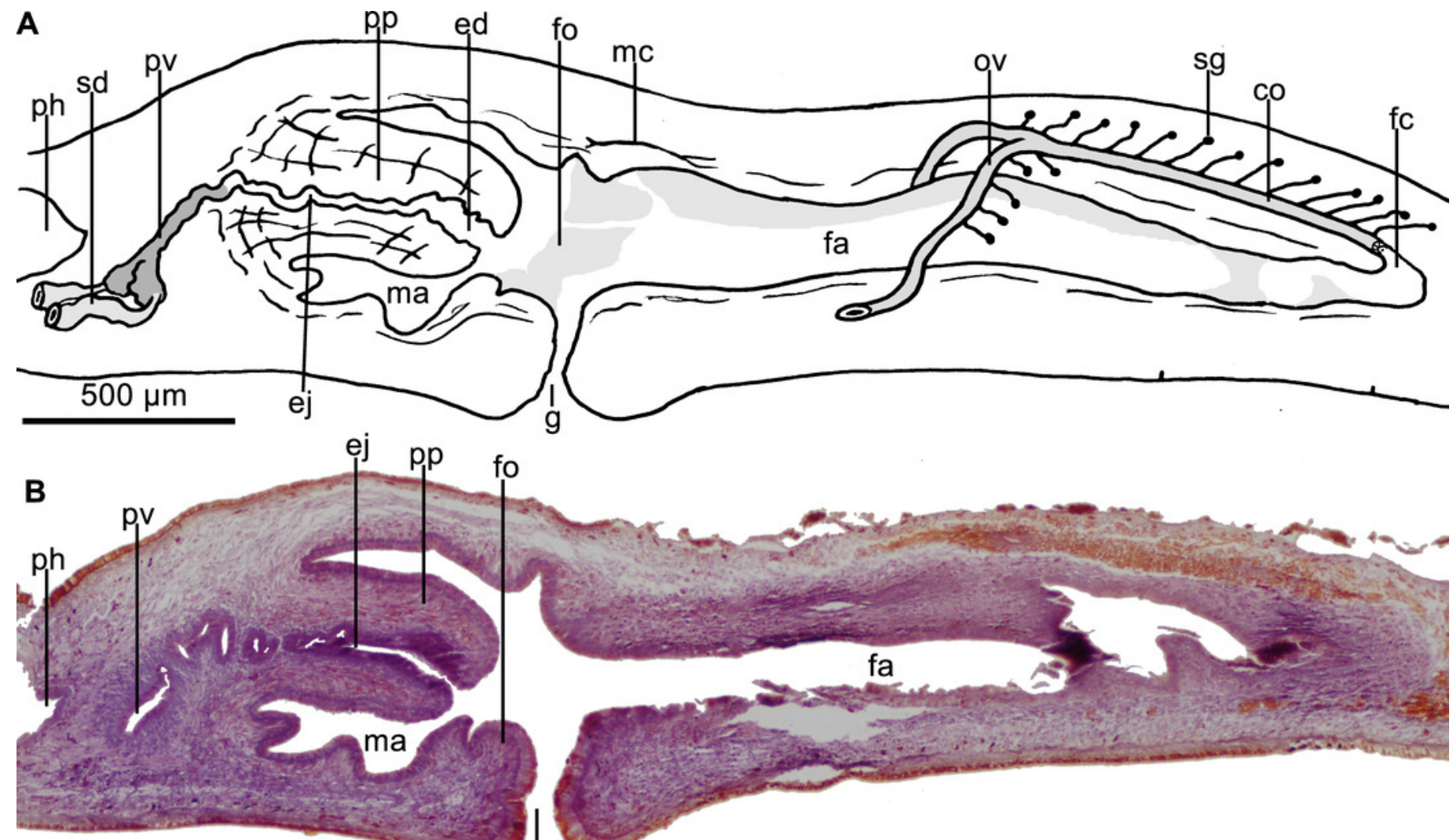

fo

$500 \mu \mathrm{m}$

C

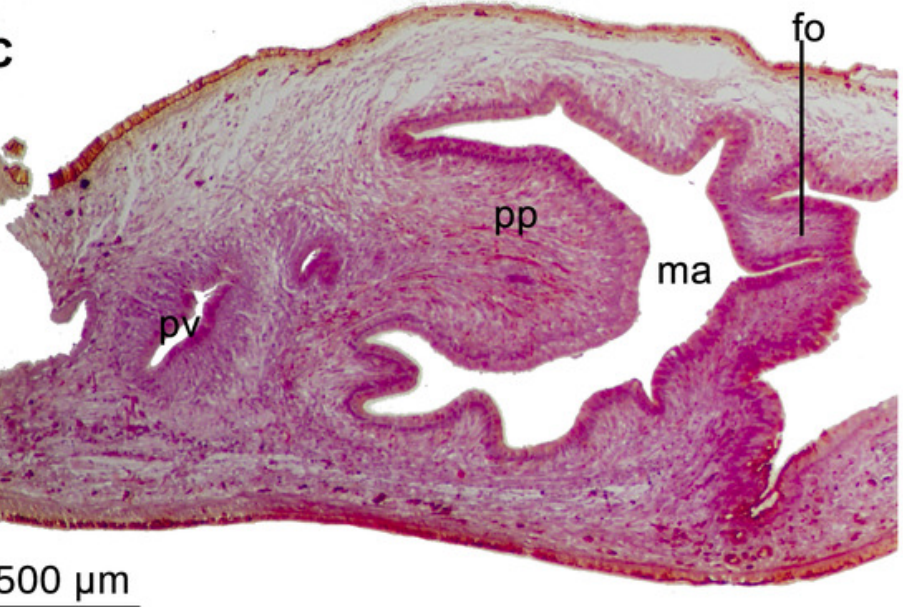

D

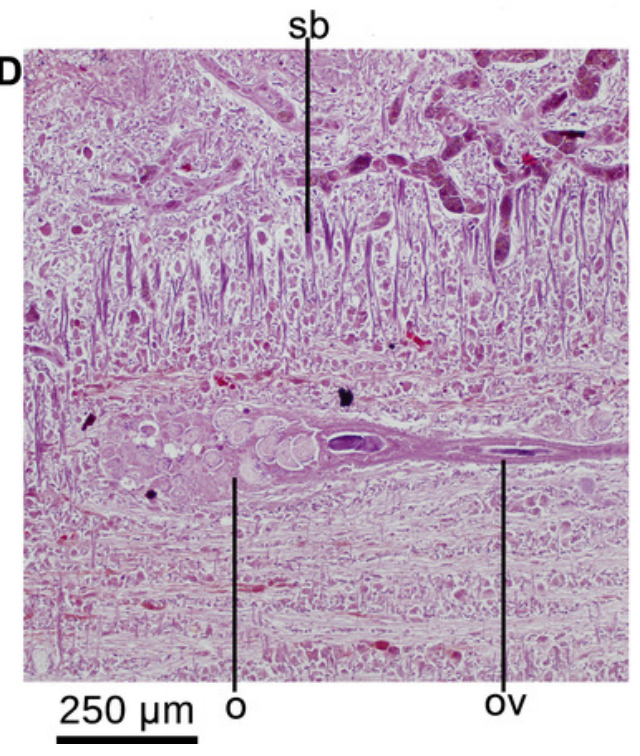




\section{Figure 14}

Cratera paraitinga sp. n. morphological features.

Cratera paraitinga sp. n. (A): Dorsal view of living holotype. (B): Dorsal view of living paratype. (C): Ventral view of living paratype. Scales not available.
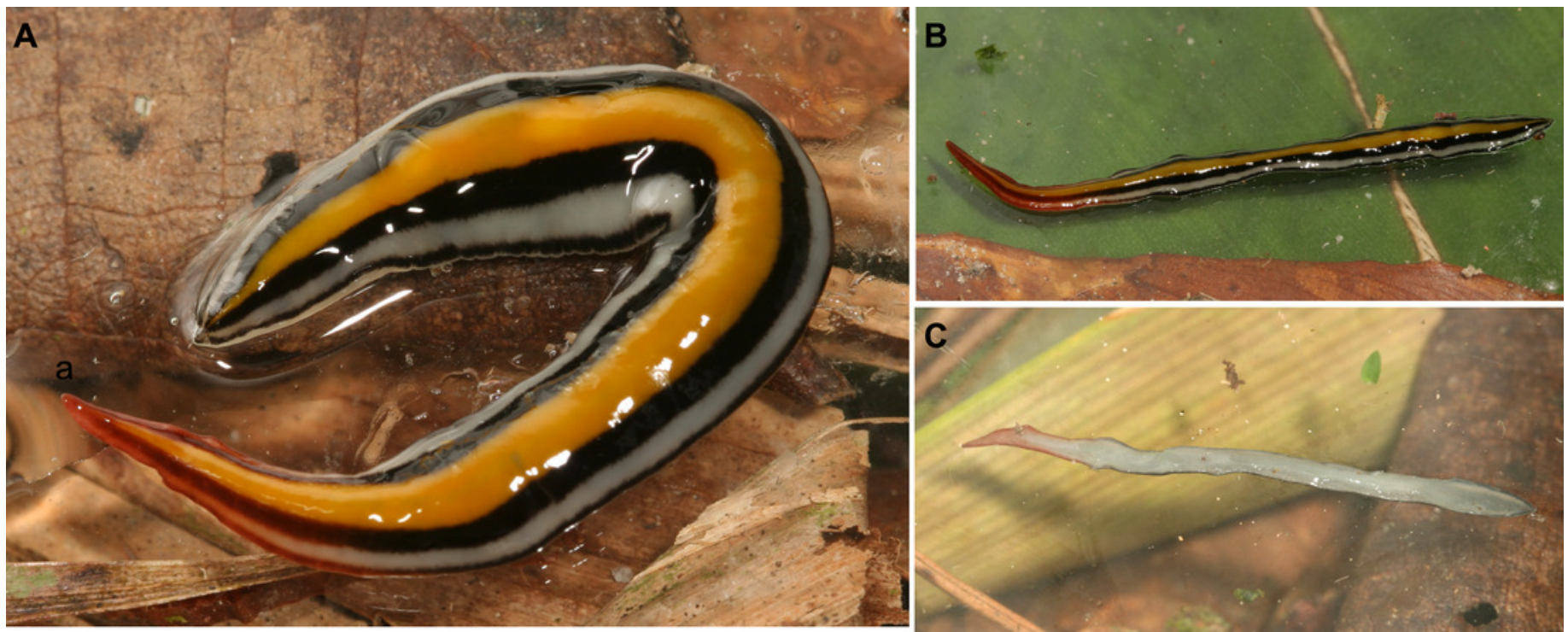


\section{Figure 15}

Cratera paraitinga sp. n. morphological characters.

Cratera paraitinga sp. n. (A): photomicrograph of a transverse section of pre-pharyngeal region of paratype. (B): photomicrograph of a sagittal section of pharynx of holotype. (C): diagrammatic representation of the copulatory apparatus of holotype from sagittal sections.
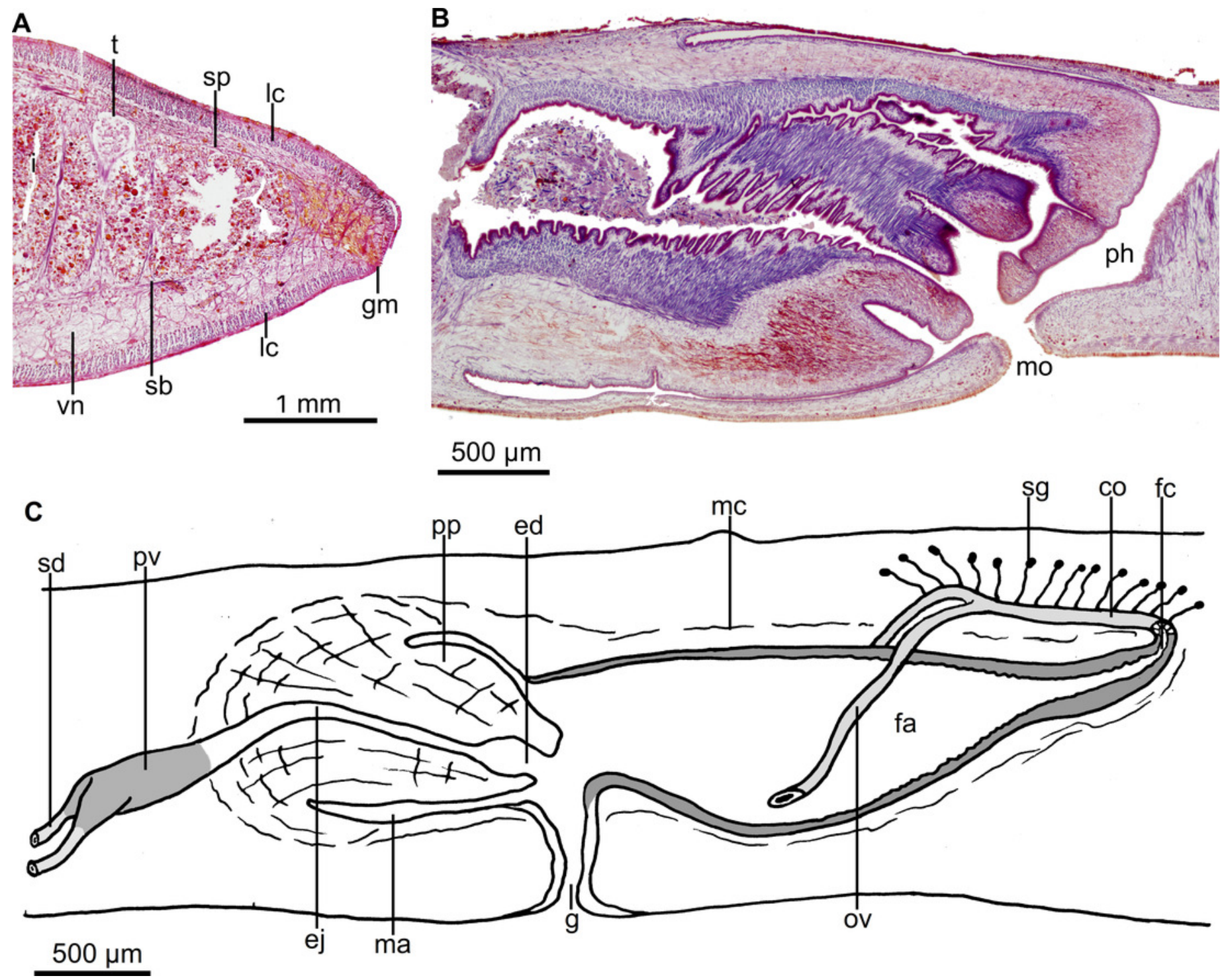


\section{Figure 16}

Cratera paraitinga sp. n. morphological features.

Cratera paraitinga sp. n. Photomicrographs of sagittal sections. (A): sagittal section of copulatory apparatus of holotype. (B): Copulatory apparatus of paratype, incompletely mature. (C): Posterior region of female atrium of holotype.
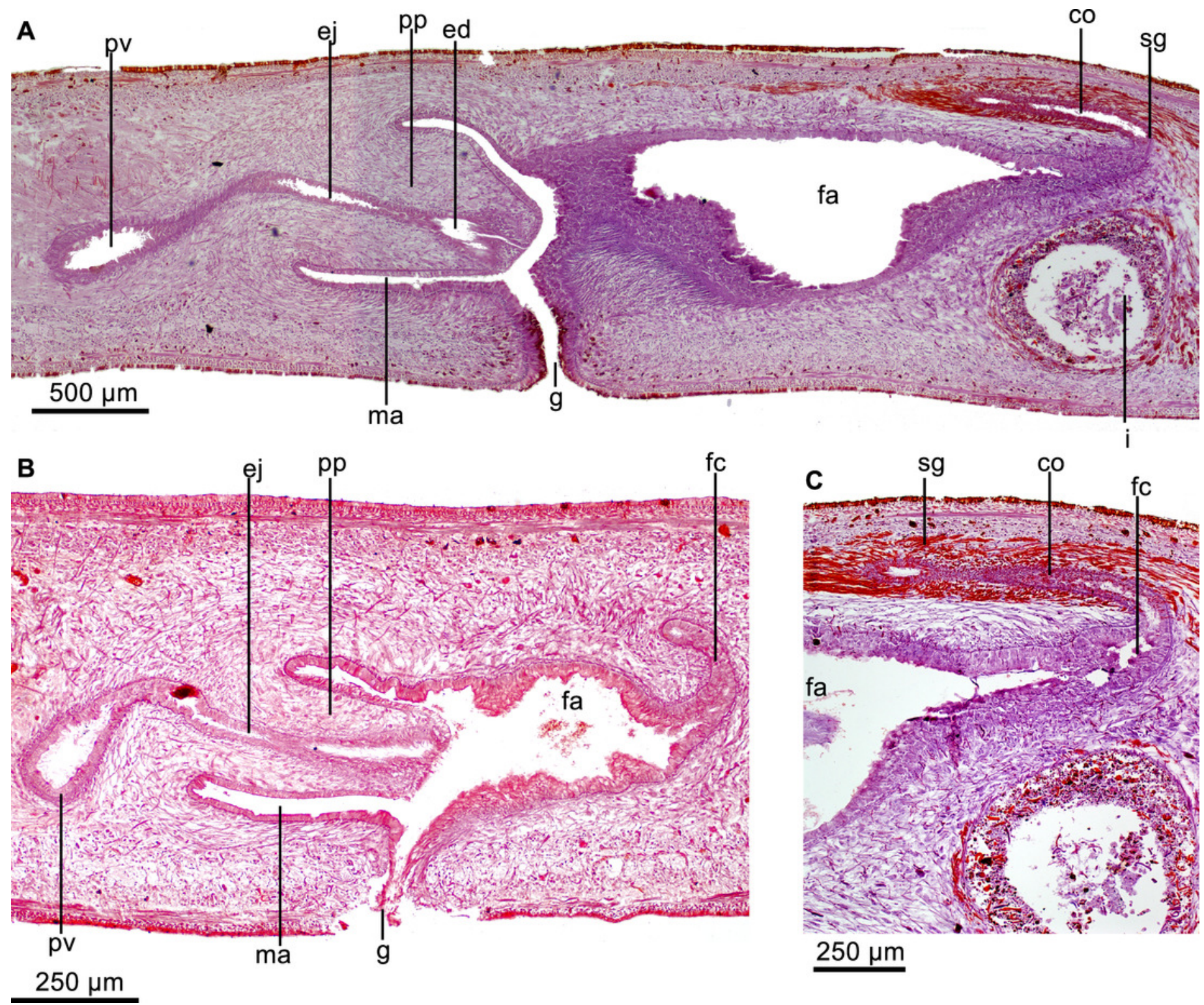
$250 \mu \mathrm{m}$ 


\section{Table $\mathbf{1}$ (on next page)}

List of Cratera samples used in this study with sampling locality, voucher code and GenBank Accession numbers.

List of Cratera samples used in this study with sampling locality, voucher code and GenBank Accession numbers. 
1 Table 1. List of Cratera samples used in this study with sampling locality, voucher code and GenBank Accession numbers.

GenBank Accession number

\begin{tabular}{|c|c|c|c|c|c|c|c|c|}
\hline Species & Sampling locality & Museum Code & Cox1 & Nd4Cox1 & $18 \mathrm{~S}$ & $28 \mathrm{~S}$ & $\mathrm{EF}$ & \\
\hline Cratera arucuia & P.N. Intervales / SP & MZUSPa PL 1048 & KC608281c & MT468629* & KC608513 & KC608396 & KC614508 & M \\
\hline \multirow[t]{4}{*}{ Cratera crioula } & P.E. Serra da Cantareira / SP & MZUSP PL 471 & MT437776* & - & - & - & - & \\
\hline & P.N. Bocaina / SP & MZUSP PL 0459 & KU564215 & - & - & - & - & \\
\hline & P.E. Serra da Cantareira / SP & MZUSP PL 1078 & KC608323 & - & KC608557 & KC608440 & KC614543 & \\
\hline & & MZUSP PL 1079 & KC608324 & - & KC608558 & KC608441 & KC614544 & $\mathrm{M}$ \\
\hline \multirow[t]{8}{*}{ Cratera cuarassu } & P.E. do Desengano / RJ & MZUSP PL 348 & MT437766* & MT468626* & KC608510 & KC608393 & KC614505 & MT \\
\hline & & MZUSP PL 349 & MT437767* & MT468627* & MT441688* & MT441711* & MT468580* & MT \\
\hline & & MZUSP PL 350 & MT437768* & - & MT441689* & MT441712* & MT468581* & MT \\
\hline & & MZUSP PL 351 & MT437769* & MT468628* & MT441690* & MT441713* & MT468582* & MT \\
\hline & & MZUSP PL 805 & MT437777* & - & - & - & - & \\
\hline & & MZUSP PL 806 & MT437778* & - & - & - & - & \\
\hline & P.E. do Desengano / RJ & MZUSP PL 807 & MT437779* & - & - & - & - & \\
\hline & & MZUSP PL 808 & MT437780* & - & - & - & - & \\
\hline Cratera imbiri sp. nov. & P.E. Campos de Jordão / SP & MZUSP PL 2155 & MT437782* & - & MT441697* & MT441720* & MT468589* & MT \\
\hline \multirow[t]{3}{*}{ Cratera ochra } & & MZU PL.00192 & KT250624 & - & - & - & - & \\
\hline & & MZU PL.00191 & KT250623 & - & - & - & - & \\
\hline & & MZU PL. 1564 & KT250622 & - & - & - & - & \\
\hline \multirow[t]{2}{*}{ Cratera paraitinga sp. nov. } & Estação Bio. Boracéia /SP & MZUSP PL 2156 & MT437783*c & MT468634* & MT441698* & MT441721* & MT468590* & MT \\
\hline & & MZUSP PL 2157 & MT437784*c & MT468635* & MT441699* & MT441722* & MT468591* & MT \\
\hline Cratera picuia & P.N. Saint Hilaire / PR & MZUSP PL 1008 & KC608261 & - & KC608493 & KC608376 & KC614491 & MT \\
\hline \multirow[t]{2}{*}{ Cratera boja sp. nov. } & P.N. Bocaina / SP & MZUSP PL 458 & MT437773* & - & MT441693* & MT441716* & MT468585* & \\
\hline & P.N. Bocaina / SP & MZUSP PL 459 & MT437774* & - & MT441694* & MT441717* & MT468586* & \\
\hline \multirow[t]{4}{*}{ Cratera assu sp. nov. } & P.N. Bocaina / SP & MZUSP PL 2146 & MT437763* & - & MT441685* & MT441708* & MT468577* & MT \\
\hline & & MZUSP PL 1050 & KC608284 & - & KC608516 & KC608399 & KC614510 & MT \\
\hline & & MZUSP PL 1052 & KC608287 & - & KC608519 & KC608402 & KC614513 & MT \\
\hline & & MZUSP PL 2150 & MT437772* & MT468631* & MT441692* & MT441715* & MT468584* & MT \\
\hline
\end{tabular}




\begin{tabular}{|c|c|c|c|c|c|c|c|c|}
\hline & & MZUSP PL 2151 & MT437775* & MT468632* & MT441695* & MT441718* & MT468587* & MT4 \\
\hline \multirow[t]{3}{*}{ Cratera tui sp. nov. } & P.N. Bocaina / SP & MZUSP PL 1014 & KC608268 & MT468625* & KC608500 & KC608383 & KC614497 & $\overline{\text { MT4 }}$ \\
\hline & & MZUSP PL 2147 & MT437764*c & - & MT441686* & MT441709* & MT468578* & MT4 \\
\hline & & MZUSP PL 2148 & MT437765* & - & MT441687* & MT441710* & MT468579* & MT4 \\
\hline Species & Sampling locality & Museum Code & Cox1 & Nd4Cox1 & $18 S$ & $28 S$ & EF & Tn \\
\hline \multirow[t]{3}{*}{ Cratera tui sp. nov. } & P.N. Bocaina / SP & MZUSP PL 2149 & MT437770*c & - & MT441691* & MT441714* & MT468583* & MT4 \\
\hline & & MZUSP PL 1051 & MT437771*c & MT468630* & KC608517 & KC608400 & KC614511 & $\overline{\text { MT4 }}$ \\
\hline & P.N. Itatiaia / RJ & MZUSP PL 2154 & MT437781* & MT468633* & MT441696* & MT441719* & MT468588* & $\overline{\text { MT4 }}$ \\
\hline \multirow[t]{2}{*}{ Cratera pseudovaginuloides } & P.N. Órgaõs / RJ & MZUSP PL 670 & KC608251 & MT468622* & KC608483 & KC608366 & KC614482 & MT4 \\
\hline & & MZUSP PL 671 & KC608252 & - & KC608484 & KC608367 & KC614483 & $\overline{\text { MT4 }}$ \\
\hline \multirow[t]{2}{*}{ Cratera tamoia } & P.N. Órgaõs / RJ & MZUSP PL 665 & KC608246 & MT468621* & KC608478 & KC608361 & KC614478 & MT4 \\
\hline & & MZUSP PL 672 & KC608254 & MT468623* & KC608486 & KC608369 & KC614484 & $\overline{\text { MT4 }}$ \\
\hline \multicolumn{9}{|l|}{ Outgroup } \\
\hline Obama anthropophila & P.N. Itajaí / SC & MZUSP PL 1007 & KC608256 & MT468624* & KC608488 & KC608371 & KC614486 & MT4 \\
\hline Obama ladislavii & & MZUSP PL 681 & KC608258 & - & KC608490 & KC608373 & KC614488 & $\overline{\text { MT4 }}$ \\
\hline Obama josefi & FLONA $^{b}$ & MZUSP PL 1075 & KC608318 & - & KC608552 & KC608435 & KC614538 & $\overline{\text { MT4 }}$ \\
\hline
\end{tabular}

